\title{
NBS
}

Eechnical Note

no. 230

\section{VHF IONOSPHERIC SCATTER SYSTEM LOSS MEASUREMENTS EUROPEAN-MEDiterRanean area}

By

V. H. Goerke and O. D. Remmler

U. S. DEPARTMENT OF COMMERCE

NATIONAL BUREAU OF STANDARDS 


\section{THE NATIONAL BUREAU OF STANDARDS}

The National Bureau of Standards is a principal focal point in the Federal Government for assuring maximum application of the physical and engineering sciences to the advancement of technology in industry and commerce. Its responsibilities include development and maintenance of the national standards of measurement, and the provisions of means for making measurements consistent with those standards; determination of physical constants and properties of materials; development of methods for testing materials, mechanisms, and structures, and making such tests as may be necessary, particularly for government agencies; cooperation in the establishment of standard practices for incorporation in codes and specifications; advisory service to government agencies on scientific and technical problems; invention and development of devices to serve special needs of the Government; assistance to industry, business, and consumers in the development and acceptance of commercial standards and simplified trade practice recommendations; administration of programs in cooperation with United States business groups and standards organizations for the development of international standards of practice; and maintenance of a clearinghouse for the collection and dissemination of scientific, technical, and engineering information. The scope of the Bureau's activities is suggested in the following listing of its four Institutes and their organizational units.

Institute for Basic Standards. Electricity. Metrology. Heat. Radiation Physics. Mechanics. Applied Mathematics. Atomic Physics. Physical Chemistry. Laboratory Astrophysics.* Radio Standards Laboratory: Radio Standards Physics; Radio Standards Engineering.** Office of Standard Reference Data.

Institute for Materials Research. Analytical Chemistry. Polymers. Metallurgy. Inorganic Materials. Reactor Radiations. Cryogenics. ${ }^{*}$ Office of Standard Reference Materials.

Central Radio Propagation Laboratory.* Ionosphere Research and Propagation. Troposphere and Space Telecommunications. Radio Systems. Upper Atmosphere and Space Physics.

Institute for Applied Technology. Textiles and Apparel Technology Center. Building Research. Industrial Equipment. Information Technology. Performance Test Development. Instrumentation. Transport Systems. Office of Technical Services. Office of Weights and Measures. Office of Engineering Standards. Office of Industrial Services.

* NBS Group, Joint Institute for Laboratory Astrophysics at the University of Colorado.

** Located at Boulder, Colorado. 


\title{
NATIONAL BUREAU OF STANDARDS Eechnical Note 230
}

\author{
Issued December 25, 1964
}

\section{VHF IONOSPHERIC SCATTER SYSTEM LOSS MEASUREMENTS EUROPEAN-MEDITERRANEAN AREA}

\author{
V. H. Goerke and O. D. Remmler \\ Central Radio Propagation Laboratory \\ National Bureau of Standards \\ Boulder, Colorado
}

NBS Technical Notes are designed to supplement the Bureau's regular publications program. They provide a means for making available scientific data that are of transient or limited interest. Technical Notes may be listed or referred to in the open literature.

For sale by the Superintendent of Documents, U. S. Government Printing Office

Washington, D.C. 20402

Price: 40 cents 

FOREWORD ..........................

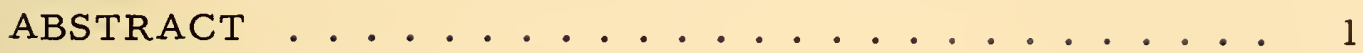

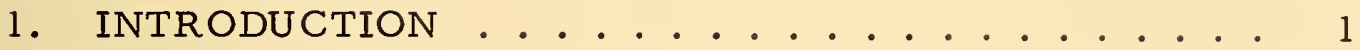

2. EXPERIMENTAL FACILITIES ........... 2

2.1 Sites and antennas .............. 2

2.2 Transmitters................. 5

2.3 Receivers.................... 5

2.4 Calibrations and bandwidths........ 6

2.5 Recording and scaling........... 7

3. RESULTS AND COMPARISONS ........... 10

3.1 Diurnal variations and cumulative distributions ................. 10

3.2 Contribution of meteoric ionization...... 16

3.3 Comparisons with earlier published results . . 16

3. 4 Galactic noise and terrestrial interference. . . 23

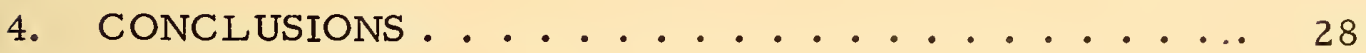

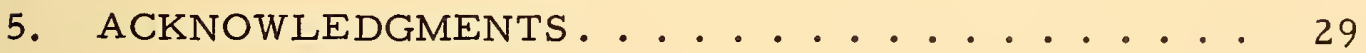

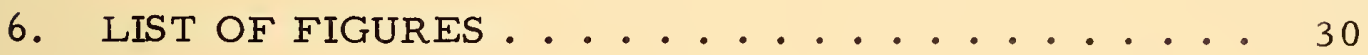

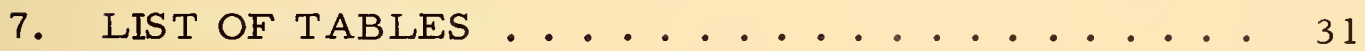

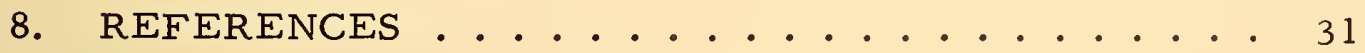

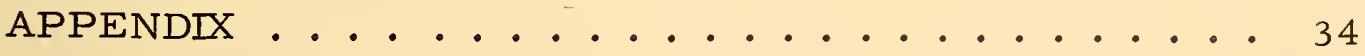


was at the desired elevation angle of $3.2^{\circ}$ (degrees) with its minimum above the main lobe many db below the maximum. The site was therefore considered very satisfactory.

The sites at Seville and Leghorn were on essentially level ground with the first Fresnel zones clear. These sites therefore were considered excellent.

The site at Tripoli did not appear to be as good as some of the others at first inspection. The site selected was on somewhat undulatory terrain with a down slope to the Mediterranean of very nearly $1^{\circ}$, as shown on figure 3. Nearly all of the first Fresnel zone was on this sloping terrain. The antenna towers were set up on the down slope with the antenna height reduced by three feet to obtain a main lobe beam at the required elevation angle. The beam elevation angle was then checked by flight tests and found to be correct within about $0.2^{\circ}$. The minimum above the main lobe was at least $24 \mathrm{db}$ down, indicating that the site was excellent for the purposes of this test.

All antenna azimuths were determined to an accuracy of $\pm 0.1^{\circ}$. The dimensions of the rhombic antennas are given in table 1 and figure 1. A $600 \mathrm{ohm}$ open wire transmission line connected the rhombic antenna to a balun and stub system 6 feet above ground level at the back tower of the rhombic. The balun and stub system transformed the impedance to $50 \mathrm{ohms}$ at the operating frequency. After initial adjustment regular checks were made to insure that the VSWR was low (it was usually less than 1.1) and that the system impedance was very near $50 \mathrm{ohms}$. A length of RG-17/U (50 ohm) cable, as short as practicable, connected the balun at the bottom of the antenna to the equipment housed in the trailer. The cable attenuation at each site was measured and 
appropriate corrections to the scaled signal and noise levels were applied to compensate for this attenuation.

\section{2 Transmitters}

Continuous wave transmissions were maintained throughout the test period using $2 \mathrm{kw}$ transmitters. By means of stable frequencycontrol equipment the transmitter frequency could be maintained within $2 \mathrm{c} / \mathrm{s}$ per day and usually within $1 \mathrm{c} / \mathrm{s}$ per day when all equipment was functioning properly. Regular carrier breaks for the purpose of measuring background noise were controlled by a pendulum clock which was regulated to within three seconds per day.

The transmitter power indicator was calibrated at regular intervals using a wattmeter operating at $50 \mathrm{ohm}$ impedance, and routine checks were made using a reflectometer which indicated the forward power, back power, and VSWR. Power was usually maintained to within a few percent of 2 kilowatts. Where output levels were appreciably different, as during periods of transmitter adjustment, such levels were noted for correction of the scaled signal strength data.

Primary power was not available at the two transmitter sites. The transmitters were powered from $20 \mathrm{KVA}$ diesel units operating at $60 \mathrm{c} / \mathrm{s}$.

\section{3 Receivers}

The receivers used were constructed by the National Bureau of Standards and had previously been used for similar measurements in the U.S. A precision, crystal-controlled local oscillator was used in conjunction with these receivers to provide signal conversion directly to the $1000 \mathrm{c} / \mathrm{s}$ IF. Image rejection of greater than $25 \mathrm{db}$ was achieved. 
Noise figures of about 3.7 decibels were maintained and checked by means of a noise generator. The nominal receiver bandwidths were $80 \mathrm{c} / \mathrm{s}$ at Leghorn for the entire test period, and $40 \mathrm{c} / \mathrm{s}$ at We ymouth, except during March 8-31 and July 4-31 when a $250 \mathrm{c} / \mathrm{s}$ bandwidth was used because the transmitter frequency was not stable enough to use the $40 \mathrm{c} / \mathrm{s}$ bandwidth. The recording time constant was 12 seconds.

The receiving stations were operated on commercial $50 \mathrm{c} / \mathrm{s} A C$ power. The receivers, signal generators, noise diode generators and other critical electronic equipments were operated with regulated voltage. During much of the several months of operation, frequency stability was very good, with the relative drift between the transmitters and receivers usually less than 1 cycle per second per day. For example, after transmitter stability problems had been cleared up in early July at Tripoli, the frequency adjustments required at the Leghorn receiving site to maintain precise tuning to the transmitter signal were less than $1 \mathrm{c} / \mathrm{s}$ per week for most of the time up to the September shutdown date.

\section{4 Calibrations and bandwidths}

Receiver calibrations were made using a crystal-controlled signal generator and techniques described by Finney and Smith [1960]. For recording purposes the zero decibel level was taken as one microvolt RMS open circuit voltage (E) across a 50-ohm (R) source, the impedance of the antenna during recording or the signal generator during calibration. Under these conditions, one microvolt represents an equivalent available power $E^{2} / 4 R$ which is 143 decibels below one watt and a system loss of 176 decibels relative to the $2 \mathrm{kw}$ transmitter output. System loss is the ratio of the radio-frequency power input to 
the terminals of the transmitting antenna to the resultant radio-frequency signal power available at the terminals of the receiving antenna [Norton, 1959; CCIR, 1959]. System loss is usually expressed in decibels.

The lowest received signal (limited by galactic background noise) was about 216 decibels system loss. Full scale on the graphic recordings was 136 decibels. With this sensitivity the minimum galactic noise level was a few decibels above the receiver noise level. The calibration was essentially linear in decibels.

At Weymouth a second receiver with considerably attenuated input was used for recording signal levels up to a system loss of 86 decibels so that low system loss values due to sporadic-E layer propagation could be recorded.

In addition to the signal generator calibration, a noise generator was used to calibrate the lower portion of the records extending up to 20 decibels above KTB noise level. The use of the noise calibration makes the measurement of galactic background levels independent of the receiver bandwidth because both calibrating and observed sources produce random noise.

A relationship between the signal generator calibration and the effective noise bandwidth (see appendix) can be obtained from a procedure due to J. W. Koch [1960]. This relationship can also be used to find the galactic noise levels for any recejver bandwidth.

\section{5 Recording and scaling}

The signal and noise levels were recorded. by the use of graphic recorders throughout the recording program. To facilitate scaling, notes were made on the records regarding VSWR, antenna condition, receiver tuning and other adjustments. Also noted were temperature, weather, sferics, precipitation and interference from known sources when observers were at the station. Calibrations were made daily and 
differences between successive calibrations were usually less than $1 / 2 \mathrm{db}$ throughout the range. To minimize drift, temperature variations in the receiving trailers were limited to about $3^{\circ} \mathrm{F}$ by means of thermostats, fans and air conditioners.

Samples of the recordings are shown in figures 4 and 5. The records for May 28 and June 19 illustrate the normal scatter trace. The spikes on the record obtained on August 12 during the Persied meteor shower are due to scatter or reflection from ionization trails produced by individual meteors. The duration of the spikes ranges from less than ten seconds to about five minutes. Both the normal and extended range recordings are shown for June 16 during a prolonged period of high signal level sporadic-E propagation. Examples of signals assumed to be propagated via the troposphere are shown in the two records from the Tripoli-Leghorn path with occasional meteor spikes projecting above the slowly varying level. Meteorological conditions along the path have not been investigated during the periods of assumed tropospheric propagation.

The record for September 19 was for a day during which the signal levels were among the lowest observed. During this period the minimum signal level and the maximum galactic noise level occurred at the same time. Even at this time of poorest signal to noise ratio, the median signal was still 15 decibels above the noise background. The interference noted during the noise break at 1830 hours was probably due to local precipitation static. In contrast, the portion of the record near 1100 hours on May 28 represents one of the highest scatter signal levels observed, 163 decibels system loss (13 db/l $\mu \mathrm{v}$ ). Day-to-day differences of scatter signal level as great as $20 \mathrm{db}$ were recorded at the same hour of the day, the highest median system losses being observed during the spring-fall period. 
The graphic recordings were scaled daily. Hourly medians centered on the half-hour and background noise levels during transmitter breaks were noted on the records in accordance with standard scaling procedures. When sporadic-E propagated signals were encountered, two medians were scaled, the first including the effect of sporadic-E and the second interpolated through as if sporadic-E had not occurred. The criterion for designating sporadic-E propagation in any hour was that sometime during the hour the signal increased abruptly to or beyond full scale (i.e.,136 decibels system loss) and sustained this level for at least one minute. To exclude unusually intense meteor burst signals the level also had to stay well above the normal scatter level continuously for at least 12 minutes. If the signal was noticeably above the normal scatter level during the hour preceding or following an hour in which sporadic-E propagation occurred, the signal was judged to be influenced by sporadic $-E$ propagation even though it did not reach full scale during that hour.

Interpolation of the scatter-signal amplitude through sporadic-E was made only for intervals of up to two hours. When sporadic-E propagated signals lasted more than two hours the interpolation was not made.

The 5-minute medians of sporadic-E propagated signals and the interference levels during transmitter breaks were scaled from the Weymouth records and analyzed.

The data were tabulated on weekly data sheets in the field. The records and tabulations were checked and further analyzed in the laboratory. The transmitter logs were examined and appropriate corrections were applied to the received field intensity for any periods when the transmitter levels were either above or below the standard $2 \mathrm{kw}$ output. 
No data were discarded except for a few hours when the receiver and transmitter were obviously out of tune and there was no way of correcting the errors introduced thereby.

\section{RESULTS AND COMPARISONS}

\section{1 Diurnal variations and cumulative distributions}

The results of the European-Mediterranean signal measurements and, for comparison, those of the Long Branch, Illinois-Boulder, Colorado path are shown in figures 6 through 13. The data from which figures 6 through 9 and figures 12 and 13 were plotted is given in table VI. For each month the following graphs are presented:

A. The diurnal variation of the hourly median system loss exceeded during $90 \%$ (upper decile), 50\% (median), and $10 \%$ (lower decile) of the days.

B. The cumulative distribution of all hourly median system losses. Note that the abscissa represents the percentage of all hours during which the system loss is less than the ordinate value. Therefore to find the system loss exceeded for a certain percentage ( $p)$ of all hours enter table VI or the graph with (100 - p) percent.

The curves on the graphs are identified in the keys on figures 6, 8, 10, and 12. System los is defined in the first paragraph of section 2.4 .

Figures 6 - 11 show also the combined data for the spring-fall months (March, April, and September) and for the summer months (May through August). No data are available for the Tripoli-Leghor $\mathbf{n}$ path for the month of March 1958, so the spring-fall data for that path are for April and September only. The results of comparisons between the various paths are given in figure 10, where the differences between 
the graphs of figures 6 through 9 have been plotted for both the diurnal variations and the cumulative distributions.

The system loss scales on all graphs decrease upwards which corresponds to an increase in signal strength. Thus the peaks of the diurnal variation graphs around midday represent high signal levels but low values of system loss. In figure 10 a positive difference indicates that the first path given at the top had the greater signal strength or smaller system loss.

The Long Branch-Boulder path is an east-west path. It is possible that east-west scatter signal levels may not be entirely comparable to north-south scatter signal levels. However, a comparison of this path with the nearly north-south paths in the European-Mediterranean area is both interesting and useful in that the data may contribute to an understanding of the effect of path orientation relative to the geomagnetic field. Signal behavior on the various paths can be seen by examining the diurnal plots and system loss distributions in figures 6 - 9 . The plots of the differences between the various graphs in figure 10 are also useful for comparison. In this figure, the differences are magnified about 4 times; i.e., 8 decibels here occupy the space of 30 decibels on other figures.

The following salient features are noted:

1. The highest observed system losses on the Seville-Weymouth path are within one decibel of those observed on the Long BranchBoulder path (see the cumulative distribution differences of figure 10). For the Tripoli-Leghorn path, the highest observed system losses are two to four decibels greater than those for the Long Branch-Boulder path. However, each of the rhombic antennas used on the Long Branch-Boulder path had one decibel more gain than those used on the European-Mediterranean paths. 
2. An examination of the diurnal-difference plots, figure 10, shows that during the spring-fall months the Seville-Weymouth path system losses are about 1 - 6 decibels above the Long BranchBoulder median system losses, while the Tripoli-Leghorn path median system losses are about 1 - 7 decibels above the Long Branch-Boulder path median system losses. For the lower deciles the differences are generally smaller than those for the median especially during the morning and evening hours. The marked differences between the Long Branch-Boulder path median system losses and those of the two European-Mediterranean paths during the period 1400-2100 hours will be discussed under 7 below.

3. For the summer months (figure 10) the system losses on the Long Branch-Boulder path are again below those for the other two paths but the diurnal differences are generally smaller for the Seville-Weymouth path and generally greater for the TripoliLeghorn path. The diurnal variation of the differences is also less than in the spring-fall case.

4. The nighttime system losses show somewhat different characteristics in that the European-Mediterranean signals do not decrease quite so rapidly after the evening maximum system losses period occurring at about 2000 as may be noted on all the diurnal difference curves comparing the Long Branch-Boulde1 path with the European paths (figure 10).

5. A comparison of the Tripoli-Leghorn and the Seville-Weymouth path, figure 10, shows a smaller diurnal variation of the difference in the median system losses than the comparisons of the two European-Mediterranean paths with the Long BranchBoulder path. Similarly, the difference in cumulative distributions vary less over the percentage range comparing the European-Mediterranean paths with each other. 
6. Aside from the diurnal variation there is only a small degree of hour to hour correlation between the variations of signal levels over the various paths. A period of moderate enhancement of signal level on one path is not particularly likely to be accompanied by a similar change on another path.

7. There is no certainty that all of the months of data are entirely typical. For the European-Mediterranean paths nearly all the data appear to follow seasonal trends consistent with those for paths previously observed. However, during July on the TripoliLeghorn path the system losses were about $3 \mathrm{db}$ high. During most of this month the transmitting rhombic antenna had about 11 feet of sag compared to the normal $5-6$ feet in the other antennas. The received signal strengths for the days immediately before the sag was reduced were compared with the data after the sag was reduced. No discernible variation was observed. On the Long Branch-Boulder path the September medians show the expected diurnal variation, except that the evening hours do not show the usual system loss increase. For this path, data are also available for September 1959. The median plot of these data shows the expected evening system loss maximum. Thus it appears that the September 1958 data for the Long BranchBoulder path are not entirely typical; the system losses for 1700-2400 hours seem abnormally low. If this is so, the differences between the European and the U.S. path signal levels during the period 1400-2100 hours noted in paragraph 2 above would be reduced.

8. The one marked difference between the Long Branch-Boulder and the European-Mediterranean data is in the relative occurrence of sporadic-E propagated signals. The occurrence 
of sporadic-E propagated signals in the European-Mediterranean area is markedly greater than for the continental USA. This difference will be discussed in greater detail in the next section.

Figure 11 shows histograms of the diurnal variation in percentage occurrence of signals propagated by sporadic-E with a system loss of less than 156 decibels (greater than $+20 \mathrm{db} / 1 \mu \mathrm{v}$ ) for all paths. This level was chosen because it is about $6 \mathrm{db}$ above the highest normal scatter signal level observed on the European-Mediterranean paths. It is about equal to the highest scatter signal levels observed on the Long Branch-Boulder path.

The greatest difference between the Long Branch-Boulder and the European-Mediter ranean paths occurred during the month of June. The average percent of occurrence of sporadic-E propagated signal levels (equal to or greater than the criterion selected) for the month of June was as follows:

$$
\begin{array}{lr}
\text { Long Branch-Boulder path } & 0.6 \% \\
\text { Seville-Weymouth path } & 12.7 \% \\
\text { Tripoli-Leghorn path } & 11.8 \%
\end{array}
$$

The difference was not so marked for the other months of the period of comparison, but both European-Mediterranean paths show a substantial excess of sporadic-E propagated signals over the Long Branch-Boulder path for all months. The difference in occurrence of sporadic-E signals between the two European-Mediterranean paths was small.

At Weymouth a second receiver operating at greatly reduced sensitivity was used. With this receiver the full range of sporadic-E signal levels could be recorded. This permitted a more complete analysis of the sporadic-E signals for the Seville-Weymouth path. During all periods of sporadic-E propagation, 5-minute median system 
loss levels were measured for the time intervals $0-5,5-10, \ldots$ 55-60 minutes after each hour. In figure 13 the cumulative distributions of these 5-minute medians are shown for the months May through September, separately and combined. In figure 12, the diurnal variation of the system loss of the sporadic-E signals is plotted as though all the 5minute medians within any hour were centered on the half-hour.

The minimum observed 5-minute median system loss of sporadic-E propagated signals was 89 decibels or $11 \mathrm{db}$ greater than the calculated inverse-distance system loss, assuming a lossless ionospheric reflection and fully realized rhombic torhombic gain. Momentary signal levels only about $6 \mathrm{db}$ greater than the inversedistance system loss were recorded.

During August on the Tripoli-Leghorn path there was a total of 201 hours during which the recorded signal was higher than the usual ionospheric scatter signal and lower than most sporadic-E propagated signals. Also the variations of the recorded trace were much slower (see figure 6). No information on the short term signal variations was obtained since a time constant of 12 seconds was used throughout. This signal was assumed to be caused by tropospheric propagation resulting from favorable meteorological conditions over the Mediterranean resulting in ducting. Near the end of August this signal dominated the records continuously for several days. Thus it is likely that this type of signal will sometimes be a useful mode of propagation at $50 \mathrm{Mc} / \mathrm{s}$ for this path. It would probably not have been observed at much lower frequencies. During September the assumed tropospherically-propagated signal was observed for only a few hours. It was not observed on the Seville-Weymouth path nor at any other time on the Tripoli-Leghorn path. 


\section{2 Contribution of meteoric ionization}

It has long been recognized that part of the observed scatter signal is the result of ionization due to micrometeorites [Bailey, et al., 1955; Eshleman, et al., 1955; Meadows, 1958]. This is in addition to the easily observed ionization produced by larger meteors. For example, in May, a month of greater meteor activity compared to April, there is a relatively greater signal enhancement at 0800 near the peak of meteor occurrence than at 2000 hours, near the minimum of meteor occurrence. This is shown in table II below.

\section{Table II}

System loss at 2000-2100 exceeds loss at 0800-0900 hours

$\begin{array}{lll}\text { Seville-Weymouth } & \frac{\text { April }}{\text { decibels }} & 10 \text { decibels } \\ \text { Long Branch-Boulder } & 9 \text { decibels } & 12 \text { decibels } \\ \text { Tripoli-Leghorn } & 7 \text { decibels } & 12 \text { decibels }\end{array}$

3.3 Comparisons with earlier published results

The results obtained by Isted [1958] at $48 \mathrm{Mc} / \mathrm{s}$ on a path from Gibraltar to the United Kingdom in March, April, and May of 1955 have been compared with the NBS results for the corresponding months of 1958. Data on the paths, antennas, and calibration systems are presented in table III. The data for the Isted system were obtained from the literature [Bain, 1958; Crow, et al., 1956; Fitch and Ruddlesden, 1958; Isted, 1958; Kitchen and Millington, 1958; Meadows, 1958; Shinn, 1958; and Williams, 1958].

At the bottom of table III the decibel levels for equal available powers are shown in each of the scales used in recording. The reference levels used are Isted's 1 microvolt across $70 \mathrm{ohms}$ matched load and the NBS results referred to 1 microvolt open circuit voltage across the $50 \mathrm{ohm}$ antenna terminals. These data are shown in ghe graph of figure 14 in system loss. 
Isted: 1955, Gibraltar-East Hanningfield (March, April, May)

NBS: 1958, Seville, Spain - Weymouth, England (March, April, May)

Patb

Frequency

Transmitter Coordinates

Receiver Coordinates

Midpoint Coordinates

Path Length

Transmitting Antennas:

Gain relative to half-wave dipole

Half-power horizontal

beamwidth

Receiving Antennas:

Gain relative to half-wave
dipole

Half-power beamwidth

Combined Antenna Gains:

Theoretical relative to dipole

Average realized relative to dipole

Desired lobe elevations and

antenna heigbts for path

lengths [Merrill, 1962]

Lobe Alignment Equivalent

Optimum for maximum power transfer

Lobe Alignment:
Gibraltar-East Hanning field

$48 \mathrm{Mc} / \mathrm{s}$

$36^{\circ} 08^{\prime} \mathrm{N}, 05^{\circ} 19^{\prime} \mathrm{W}$

$51^{\circ} 41^{\prime} \mathrm{N}, 00^{\circ} 34^{\prime} \mathrm{E}$

$43^{\circ} 54^{\prime} \mathrm{N}, 02^{\circ} 22^{\prime} \mathrm{W}$

1110 miles, $1786 \mathrm{~km}$

$4 \times 4$ curtain with reflectors

$16 \mathrm{db}$

$20^{\circ}$

$1 \times 8$ vertical stack of halfwave dipoles with reflectors

$12 \mathrm{db}$

$84^{\circ}$

$28 \mathrm{db}$

$17 \mathrm{db} \quad$ [Shinn, 1958]

$2.9^{\circ}, 115 \mathrm{ft}$.

$2.3^{\circ}, 145 \mathrm{ft}$.

$1.8^{\circ}, 175 \mathrm{ft}$.
Seville-Weymouth $49.8 \mathrm{Mc} / \mathrm{s}$ $37^{\circ} 09 ! \mathrm{N}, \quad 05^{\circ} 35^{\prime} \mathrm{W}$ $50^{\circ} 38^{\prime} \mathrm{N}, 02^{\circ} 22^{\prime} \mathrm{W}$ $43^{\circ} 54^{\prime} \mathrm{N}, 04^{\circ} 09^{\prime} \mathrm{W}$ 944 miles, $1520 \mathrm{~km}$ Long wire rhombic

$18 \mathrm{db}$

$6^{\circ}$

Long wire rhombic

$18 \mathrm{db}$

$6^{\circ}$

$36 \mathrm{db}$

18 to $25 \mathrm{db}$

[Bailey, et al, 1955]

Lobe elevations for antenna heights used (assuming sea foreground) [Merrill, 1962]

Transmitter: 1st lob

$0.4^{\circ}, 700 \mathrm{ft}$

$3.2^{\circ}, 103 \mathrm{ft}$.

2nd lobe $1.2^{\circ}$

3rd lobe $2.1^{\circ}$

4 th lobe $3.0^{\circ}$

Receiver: lst lobe

$4.2^{\circ}, 80 \mathrm{ft}$. to center of stack

$3.2^{\circ}, 103 \mathrm{ft}$.

Power to Transmitting Antenna, $\mathrm{P}_{\mathbf{t}}$

Receiver Calibration Scales

Decibels relative to $l \mu v$ across 70 ohms, matched load conditions

$2 \mathrm{kw}$

Decibels relative to $1 \mu \mathrm{v}$ open circuit antenna voltage, 50 ohm antenna

Formula for power available, $\mathrm{P}_{\mathrm{a}}$, to a matched load, voltage as specified above:

$P_{a}=E^{2} / R=E^{2} / 70 \quad P_{a}=E^{2} / 4 R=E^{2} / 200$

\section{COMPARISON OF VARIOUS SCALES USED}

$\mathrm{db}$ above 1 watt

$\mathrm{P}_{\mathrm{t}}$ : To transmitting antenna Isted $(40 \mathrm{kw})$ NBS (2 kw)

$$
46.0
$$$$
\text { 33. } 0
$$

$\mathrm{db}$ above $1 \mu \mathrm{v}$ across $70 \mathrm{ohm}$ matched (Isted) $\mathrm{db}$ above $1 \mu \mathrm{v} \quad$ System loss open circuit Isted NBS

$50 \mathrm{ohm}$ antenna (40 kw) (2 kw) (NBS)

$P_{a}$ : Available to receiver matched to antenna

\begin{tabular}{l|llll}
-138.5 & 0 & 4.5 & 184.5 & 171.5 \\
-143.0 & 0 & 189.0 & 176.0 \\
& & & & \\
& & & & \\
\hline
\end{tabular}


The NBS data are replotted from the monthly-median diurnal variations given in earlier figures. The Isted data are taken from a smoothed curve drawn through the monthly mean values of thirty-minute medians [Isted, 1958]. The NBS data are based on substantially continuous records while the Isted data are based on an average of 16 daily record samples per month. Only three or four of the se are nighttime records.

A change in Isted's receiving antennas, from a single dipole and reflector to a stack of 8 dipoles and reflectors made in mid-March, was compensated by adding $8 \mathrm{db}$ to the data obtained with a dipole [Isted, 1958]. Because no transmissions were made from Gibraltar at certain hours in March and April, lack of data made interpolation necessary; the interpolated points are shown as solid circles on the plots. Where some of the thirty-minute medians exceeded the recorder range, the monthly mean is plotted with an upward-pointing arrow. Note that the system loss scale is different on the graph for May in figure 14 than for March and April. An indication of the overall system-loss differences is given in table IV. System loss values were taken from the monthly cumulative distribution curves.

Table IV

$$
\text { March April May }
$$

System Los s Isted NBS Diff. Isted NBS Diff. Isted NBS Diff.

$\begin{array}{llllllllll}\text { Exceeded } 90 \% & 194 & 178 & 16 & 190 & 180 & 10 & \sim 175 & 169 & \sim 6\end{array}$
of month

Exceeded $50 \% \quad 197 \quad 185 \quad 12$ of month

Exceeded 10\% $202 \quad 189 \quad 13$ of month 
It is at once apparent from the graphs that there are marked differences in the shape of the diurnal variation curves -- and less marked differences in the general levels (the Isted antenna had a combined theoretical plane-wave gain some $8 \mathrm{db}$ less than that of the NBS rhombics; see table III). The authors of this report believe that the se discrepancies can be explained on the basis of great differences in the effective antenna patterns, particularly that of the Gibraltar transmitting antenna which, because of geographical conditions beyond economic control, had to be placed considerably higher than desired above a hilly foreground.

In general, it is felt that the Isted experiments favored scattering from off-path meteor trails, while the NBS experiments were directed toward a smaller common volume along the great circle path between transmitter and receiver. The effects of differing antenna characteristics on the diurnal variations are discussed by Smith [1959]. In what follows, frequent references will be made to reports of the tests as presented at the Symposium on Long-Distance Propagation Above $30 \mathrm{Mc} / \mathrm{s}$, which was held in London in January 1958 by the Institution of Electrical Engineers.

The antennas used by NBS were long-wire rhombics having a half-power beamwidth of $6^{\circ}$, with the center of the lobe directed at a point 85 kilometers above the path midpoint. This lobe alignment was determined from data given by Merrill [1960, 1962]. The flat terrain or sea at both ends of the path assured that the correct lobe elevations were actually achieved. In the case of the Weymouth site, the lobe elevation was verified by means of a target transmitter in an airplane. The information in the reports [Merrill, 1960, 1962] were also used to obtain the lobe elevations given in table III for the Isted antennas. 
The desired lobe elevations are based on the actual path length of 1786 kilometers. The four lobe elevations for the transmitting antenna at Gibraltar are based on the 700-foot height given by Meadows [1958], and an assumed smooth, spherical earth foreground (the actual foreground will be discussed shortly).

Since no information could be found in the symposium reports regarding the elevation of the receiving antenna lobe, the midpoint of the $1 \times 8$ stack of dipoles was estimated to be 80 feet high from a photograph of the antenna in which some other dimensions were known. The resulting elevation of the first lobe was found to be $4.2^{\circ}$. Even the top-most dipole of the stack, at about 125 feet, was barely above the lobe-alignment equivalent height of 115 feet, as determined from Merrill's [1960] report. Thus it is difficult to understand how the receiving antenna could have illuminated the common volume at a height of 85 kilometers. It seems likely that meteor-trail heights around $100 \mathrm{~km}$ would have been favored.

From diagrams and descriptions in some of the symposium papers [Isted, 1958; Meadows, 1958; Kitchen and Millington, 1958; Fitch and Ruddlesden, 1958; Williams, 1958, and Bain, 1958], the situation at the Gibraltar site was as follows: Five-hundred-foot high hills, about four miles in front of the antenna, would have intercepted ground reflections at elevations of less than about $3^{\circ}$. At 23 miles, another ridge some 3000 feet high intercepted all radiation below an elevation of about $1^{\circ}$. Fitch and Ruddlesden [1958] indicate that at best, if some lobes had been formed, the illumination of the ionosphere would have been striated with an overall result $3 \mathrm{db}$ greater than for a free space antenna which may even be optimistic in view of lack of coherence between direct and ground reflected signals. For a scaled 
antenna at $37.3 \mathrm{Mc} / \mathrm{s}$, the horizontal direction of the major lobe, as measured by Crow, et al. [1956] appears to have been several degrees to the west of the great circle path to East Hanningfield, the receiving site. The horizontal half-power beamwidth of the array used at Gibraltar was given as $20^{\circ}$, though no measured azimuthal pattern at $48 \mathrm{Mc} / \mathrm{s}$ was given.

At Slough, some 50 miles west of East Hanningfield, Bain [1958] measured the diurnal variation of the mean bearing of signals at 37.3 $\mathrm{Mc} / \mathrm{s}$ received from Gibraltar and found that it deviated to the west an average of $7^{\circ}$ during the night and $0^{\circ}$ during the day. At Winkfield, near Slough, Meadows [1958] confirmed Bain's result by measuring the direction of arrival of reflections from meteor trails of the 37.3 $\mathrm{Mc} / \mathrm{s}$ signal from Gibraltar.

Meadows also found that the number of reflections arriving per degree of elevation was approximately constant over the range $1-5^{\circ}$ and fell rapidly in the region of $6-7^{\circ}$. This implies (from path geometry considerations) apparent reflection heights around $100 \mathrm{~km}$. He discusses the underlying reasons for the above observations in terms of the motion of the earth in its orbit and its daily rotation. These results agree with the studies of other workers [Smith, 1959; Bailey, 1955].

Measurements on a north-south path by Hagfors [1962] show that at midday most of the meteor bursts are received from the eastern side of the path whereas around midnight the majority of the bursts are from the west side of the path. At both times a minimum in the number of bursts was seen along the great circle path.

Since the Isted path was $18 \%$ longer than the NBS path an estimate of the increase of system loss for the longer path should be made in order to compare the results with the NBS measurements. The distance 
dependence as shown [JTAC, 1960] for optimum-height ideally-sited antennas of the type used by NBS, indicates a system loss about 3 decibels greater for the longer path. It is probable that the system loss is greater for antennas of larger beamwidth or with multiple lobes.

The differences between the Isted results and the NBS results may now be explained on the basis of the above observations. The narrow-beam NBS antennas directed toward a comparatively small scattering volume above the path midpoint would discriminate somewhat against meteors, but, at the same time, the diurnal variations would show a strong solar influence [Bailey, et al, 1955]. Isted's [1958] broadbeam antennas, with the transmitting antenna major lobe directed somewhat to the west of the great circle path and the receiving antenna pattern directed above the 85 -kilometer height, would be principally influenced by meteoric ionization. Therefore, an increase in the number of meteors should have caused a greater increase in the Isted signal levels than in the NBS signal levels.

The response of Isted's [1958] system to the increased influx of meteors during May is evident in figure 14, in which the meteoric maximum around 0800 is more pronounced than in March or April. In going from April to May the increases in Isted's signals, at the times of day of both maximum and minimum meteoric activity, were far larger than for any of the three NBS paths described under section 3.2. In fact, in May the general level of the diurnal curve for the Isted signals is much closer to the NBS curve, especially during the night when the effect of meteoric ionization is greatest.

Table IV indicates that the monthly median system loss was 4 to $12 \mathrm{db}$ greater for Isted's system. This must, according to the definition of system loss [Norton, 1959], be explicable by differences in the 
antenna systems and the associated terrain, assuming comparable ionospheric conditions. Several decibels of this difference could be accounted for by the poor foreground at Gibraltar and another 1 to $3 \mathrm{db}$ by the greater path length. It is indicated [Bailey, et al., 1955] that any remaining differences in system loss are well within the differences in realized gains expected for such different antenna systems. The Isted group realized an average gain of $17 \mathrm{db}$ relative to half-wave dipoles for their antennas [Shinn, 1958]. While no actual measurements of realized gain were made on the NBS system, figure 56 of the report by Bailey, Bateman and Kirby [1955] gives cumulative distributions of realized gains for similar antenna systems, the median values ranging from 18 to $25 \mathrm{db}$. The same reference shows that the diurnal variation of realized gain is much greater for rhombic antenna systems than for wide beam Yagi antenna systems, the rhombics having a broad maximum during daylight hours. This would explain why the greatest differences in system loss, figure 14, occur during the late morning and afternoon hours when meteoric ionization is low. At this same time, the realized gain of the rhombic system is greatest because solar radiation is most effective in ionizing the 85-kilometer scattering region. According to a study made by Ellyett and Leighton [1958], it is also possible that midday scatter signal levels were 2 to $3 \mathrm{db}$ lower during the sunspot-minimum year of 1955 than near the sunspot maximum in 1958.

In view of all the above considerations, the NBS and Isted results seem more compatible than was first believed.

\subsection{Galactic noise and terrestrial interference}

In ionospheric scatter systems using low-noise receivers, the galactic background is the lowest observable noise level in the absence 
of interference from terrestrial sources. The diurnal variation of galactic noise actually observed at a given site is predictable from the antenna pattern, its elevation and azimuth, and the time of day. As the antenna beam rotates with the earth it scans the heavens in the direction of increasing right ascension and at a constant declination. Whenever the beam passes through the plane of the galaxy the background noise shows a peak. For a given time of observation the right ascension seen by the main lobe increases about four minutes each day because of the earth's revolution about the sun. One method of predicting the diurnal variation is to use a set of galactic charts [Menzel, 1960].

Figures 15 and 16 are mass plots of the measured background noise levels for one month at Weymouth and Leghorn. The effect of any interference during the transmitter breaks has been eliminated by interpolation where possible. The data in terms of decibels above KTB are plotted against right ascension, which was determined from the direction of the antenna beam and the time of observation.

The declination in celestial coordinates of the main lobe at Weymouth was $35.3^{\circ}$ south of the celestial equator while at Leghorn it was $39.5^{\circ}$ south. The center of the radio galaxy is in the constellation Sagittarius at about $30^{\circ}$ south, which accounts for the slightly higher levels seen by the Weymouth antenna. The maxima near right ascension 0900 and 1700 hours correspond to the passage of the plane of the galaxy (Milky Way) through the antenna lobe -- the larger maximum being nearer the galactic center. The 3 or $4 \mathrm{db}$ spread in the galactic noise levels is due to varying ionospheric absorption at the low elevation angle of the antenna beam. The measured levels are about $3 \mathrm{db}$ below the levels estimated from galactic charts using a $6^{\circ}$ half-power beamwidth probably because the directivity gain corresponding to this 
half-power beamwidth is $21 \mathrm{db}$, while the measured power gain of the rhombics is only $18 \mathrm{db}$. The difference between directivity gain and power gain is equal to antenna copper losses and nearby ground losses as well as the loss in the terminating resistors. The last, when computed for these antennas, was found to be $2.8 \mathrm{db}$ [Schelkunoff and Friis, 1952].

While galactic noise-level measurements were not made at the transmitting sites, the antennas were pointed to northerly declinations well away from Sagittarius so that had one placed receivers at those sites the maximum noise levels encountered would have been 3 to 5 decibels below the levels seen at the receiving sites. See also section 2. 4 for application of galactic noise data to practical systems.

Interference during transmitter breaks was observed only rarely, and then almost always at levels well below the scatter or sporadic-E propagated signal. Some analysis was thought desirable to determine the most probable origins of the interference and the effect of sporadic-E propagation.

The maximum interference levels during the two-minute transmitter breaks were scaled from the Weymouth records for the period May lst through September 26th, except July 4 - 31 when the bandwidth was $250 \mathrm{c} / \mathrm{s}$ instead of the regular $40 \mathrm{c} / \mathrm{s}$. Only those levels which exceeded the expected galactic noise by more than $2 \mathrm{db}$ were scaled. Known instances of local ignition, sferics and precipitation static were eliminated in scaling. The remaining interference was probably from the following sources:

1. Manmade noise from ignition, power lines, or electrical apparatus. 
2. Radio or radar transmitters on or near the signal frequency or its subharmonics.

3. Sferics or precipitation static.

4. Some of the above types propagated to the receiving site by sporadic-E.

During the period studied, there were 5586 usable transmitter breaks including 419 cases of recognizable interference which exceeded the galactic level by more than $2 \mathrm{db}$. The peak level was always measured even though it lasted for only a fraction of the two-minute break in most cases. Both the interference and the transmitter breaks were classified according to whether or not sporadic-E propagation of the scatter signal occurred within one hour. A mass plot of the data was made which preserved the distinction between the two classes. The results are summarized in figure 17 (see key on opposite page).

Figure 17A shows the diurnal variation of all interference for the peak levels exceeded during $1 \%, 2 \%$, and $5 \%$ of the transmitter breaks. The diurnal variation of galactic noise is shown in figure $17 \mathrm{~A}$ as it would appear on September 30 when the maximum occurs at 1800 . The entire diurnal curve of the galactic background shifts toward earlier hours at the rate of about two hours per month. Thus, for example, on October 30 the maximum would occur at 1600 and on July 30 at 2200 hours. In figure $17 \mathrm{~B}$ the cumulative distributions of all the interference and of the galactic noise observed in a $40 \mathrm{c} / \mathrm{s}$ passband are plotted separately.

Most of the interference occurred during local working hours, and the pronounced minimum at midday suggests that its origin is principally local man-made noise. The antenna beam was directed out 
over Ringstead Bay and just to the east of Portland Harbor, an active naval base. Occasionally ignition noise was heard when boats were in the beam. There was a small seashore community one-third of a mile east of the site and agricultural tractors were operated in the vicinity.

For figure $17 \mathrm{C}$ and $\mathrm{D}$ the two classes of interference were analyzed separately, each based on its own population of transmitter breaks. These figures demonstrate a tendency for the strongest interfering signals to occur when sporadic-E propagation conditions exist. In both graphs, the highest interference levels ever observed are indicated by small squares along with the peak levels exceeded during $2 \%, 5 \%$, and $10 \%$ of the transmitter breaks. The noon-hour minimum is most definite under sporadic-E conditions, which probably eliminates distant radio transmitters and natural phenomena as the major sources of the interference. On such a north-south path, along which the noonhour recess from work may occur simultaneously at many points, manmade noise could have been the most likely source of the interference.

An indication of the relative unimportance of interference at the Weymouth site is given by including selected ionospheric scatter levels on the graphs in figures 17B, C, and D (see key).

No detailed study of the interference at the Leghorn site was made. However, an inspection of the records indicated that the frequency of occurrence and amplitude of interference were certainly no worse than at Weymouth. This is somewhat reassuring since the antenna beam was pointed almost directly toward Leghorn some 7 to 10 miles distant. There was no observable noise directly attributable to the electric railway systems in the area. During severe storms, the noise level was somewhat higher than for Weymouth, which may have 
been due to the effect of strong winds and rain on local power lines. During heavy rainstorms at both sites, precipitation static and interference from nearby lightning discharges sometimes produced noise levels equal to or a few decibels above the scatter signal. While these noise levels will affect the error rate of a scatter system their occurrence is quite rare and some techniques are available for reducing the level of precipitation-static.

\section{CONCLUSIONS}

The experimental systems and techniques used on two ionospheric forward-scatter paths at $50 \mathrm{Mc} / \mathrm{s}$ in the European-Mediterranean area have been described.

The results of measurements are described in detail in graphs and text material. A summary of system loss values taken from the cumulative distributions appears in table $\mathrm{V}$ below.

\section{Table V}

Summary of System Loss Values

in Decibels for Three Paths

\begin{tabular}{|c|c|c|c|c|}
\hline Season & $\begin{array}{l}\text { Percent } \\
\text { of Hours* } \\
\end{array}$ & $\begin{array}{c}\text { Seville- } \\
\text { Weymouth } \\
\end{array}$ & $\begin{array}{c}\text { Long Branch- } \\
\text { Boulder } \\
\end{array}$ & $\begin{array}{l}\text { Tripoli- } \\
\text { Leghorn } \\
\end{array}$ \\
\hline Spring-Fall & $50 \%$ & 185 & 182 & 186 \\
\hline Spring-Fall & $90 \%$ & 190 & 188 & 181 \\
\hline Spring-Fall & $99 \%$ & 192 & 192 & 195 \\
\hline Summer & $50 \%$ & 180 & 177 & 183 \\
\hline Summer & $90 \%$ & 186 & 184 & 190 \\
\hline Summer & $99 \%$ & 190 & 189 & 193 \\
\hline
\end{tabular}

* System loss is equal to or less than the specified value for these percentages of time. 
It is evident that the Seville-Weymouth values are statistically comparable with those for the Long Branch-Boulder path, recognizing that the former path is longer (see table I and [JTAC, 1960]). This is true in spite of the differences in path orientation. On the other hand, the relatively greater system loss values for the Tripoli-Leghorn path which is of comparable length would suggest some influence of the geomagnetic location of the scattering region, system loss being greater as one goes farther south.

Sporadic-E propagated signals were observed much more frequently in the European-Mediterranean area than in the United States. During June sporadic-E was in evidence 25 times as long in the European-Mediterranean area. The ionospheric scatter signal levels observed on the two European-Mediterranean paths are not greatly different from levels measured in the USA. The unusual variations and low signal levels observed in 1955 by Isted [1958] on $48 \mathrm{Mc} / \mathrm{s}$ transmitted from Gibraltar to England, have been explained on the basis of antenna patterns which favored off-path and higher-level scattering by meteoric ionization. Galactic noise levels at both receiving sites have been presented, together with an analysis of the interference observed at the receiving site in England. The observed galactic noise levels are in good agreement with predictable levels.

\section{ACKNOW LEDGMENTS}

The accomplishment of the se experiments is due in large measure to our NBS colleagues who manned the field stations and kept transmitters and receivers operating 24 hours a day with remarkably few outages. The work of Milton W. Woodward, who with great resourcefulness kept a single, early model of the transmitter on the 
air at Moron, Spain, is especially commendable. Valuable assistance was provided at all stations by airmen and non-commissioned officers assigned by the U.S. Air Force, 1823rd AACS Group. Logistical and financial matters were ably handled by the American Embassies and the U.S. Air Force. The help and encouragement so cheerfully given by Mr. C. F. Sutton of the British Air Ministry are greatly appreciated.

\section{LIST OF FIGURES}

Figure

Number

\section{Title}

1.

Details of rhombic antennas

2. Photographs of sites

3. Terrain profile of Libya site

4. Sample recordings (6 - 5-hour records)

5. Sample recordings (3 - 12-hour records)

6. Diurnal variation during spring-fall months

7. Diurnal variation during summer months

8. Cumulative distribution for spring-fall months

9. Cumulative distribution for summer months

10. Differences between observed system losses (3 paths for summer months and spring-fall)

11. Percent of time sporadic-E propagated signal was present

12. Diurnal variation of sporadic-E signals at Weymouth

13. Cumulative distribution of sporadic-E signals at Weymouth

14. Comparis on with Isted 1955 results

15. Observed galactic noise levels, Weymouth, England

16. Observed galactic noise levels, Leghorn, Italy

17. Interference observed at Weymouth, England (faced by key) 
Table

7. LIST OF TABLES

Number

Page

Number

I

Details of experimental paths

Number

II System loss at 2000-2100 exceeds loss at

3

0800-0900 hours ............... 16

III Comparison data ............... 17

IV Isted-NBS data comparison ........ 18

$\mathrm{V} \quad$ Summary of system loss values in decibels

for three paths ............... 28

VI Data for figures $6-9$ and $12-13 \quad 54-58$

VII Effective noise bandwidths ........ 36

\section{REFERENCES}

Bailey, D. K., R. Bateman, and R. C. Kirby (October 1955), Radio transmission at VHF by scattering and other processes in the lower ionosphere, Proc. IRE 43, 1181-1230.

Bain, W. C. (1958), The angular distribution on energy received by ionospheric scattering at very high frequencies, Proc. IEE 105, Part B, Supplement No. 8, 53-55.

Blair, J. C., R. M. Davis, Jr., and R. C. Kirby (Sept.-Oct. 1961), Frequency dependence of D-region scattering at VHF, J. Res. NBS, 65D (Radio Prop.), No. 5, 417-425.

CCIR (1959), Documents of the IXth Plenary Assembly, Los Angeles, 1959, 1, Recommendation 241, The concept of transmission loss in radio systems studies, International Telecommunication Union, Geneva, Switzerland.

Cohen, R. S., and K. L. Bowles (Sept. -Oct. 1963), Atmospheric VHF scattering near the magnetic equator during the International Geophysical Year, J. Res. NBS, 67D (Radio Prop.), No. 5, 459-480. 
Crow, D. A., F. A. Kitchen, G. A. Isted, and G. Millington (1956), A disturbing factor in very high frequency communications via ionospheric forward scatter, Nature, 178 No. 4545, 1280-1283. Ellyett, C., and H. Leighton (October 1958), Solar cycle influence on the lower ionosphere and on VHF forward scatter, Proc. IRE. 46, No. 10, $1711-1716$.

Eshleman, V. R., L. A. Manning, A. M. Peterson, and O. G. Villard, Jr. (1955), The role of meteors in extended-range VHF propagation, IRE Convention Record, Part 1, Antennas and Propagation, 61-62.

Finney, J. W., and E. K. Smith, Jr. (March 1960), Report on the IGY oblique-incidence sporadic-E and F-scatter program, NBS Technical Note $48,36$.

Fitch, E., and R. Ruddlesden (1958), The choice of aerial height for ionospheric scatter links, Proc. IEE 105, Part B, Supplement No. 8, 12-18.

Goldman, S. (1948), Frequency analysis, modulation and noise, p. 254, (McGraw Hill Book Co., Inc., New York, N. Y.).

Hagfors, T. (July-August 1962), On the forward scattering of radio waves in the lower ionosphere, J. Research NBS, 66D, (Radio Prop.), No. 4, 409-418.

Isted, G. A. (January 1958), Analysis of Gibraltar-United Kingdom ionospheric scatter signal recordings, Proc. IEE 104, Part B, 2523.

JTAC (January 1960), Joint Technical Advisory Committee on Forward Scatter Transmission Report, Radio transmission by ionospheric and tropospheric scatter, Proc. IRE $\underline{48}, 3-31$.

Kirby, R. C. (October 6-7, 1958), 1958 critique of VHF ionospheric scatter communication, record of the IRE National Symposium on Extended Range and Space Communications, pp. 90-95 (George Washington University, Washington, D. C.) 
Kitchen, F. A., and G. Millington (1958), Survey of the GibraltarUnited Kingdom ionospheric scatter measurements, Proc. IEE 105, Part B, Supplement No. 8, 2-6.

Koch, J. W. (1960), Private communication.

Meadows, R. W. (1958), The direction and amplitude of reflections from meteor trails and sporadic-E ionization on a $1740 \mathrm{~km}$ north-south path at VHF, Proc. IEE 105, Part B, Supplement No. $8,56-64$.

Menzel, D. H. (1960), A study on cosmic radio noise sources, pp. 151 176 in The Radio Noise Spectrum (Harvard University Press, Cambridge, Mass.)

Merrill, R. G. (March 1960), Optimum antenna height for ionospheric scatter communication, 1959 IRE National Convention Record, IRE Trans. Commun. Systems, CS-8, Pt. 1, 10-18.

Merrill, R. G. (April 1962), Radiation patterns in the lower ionosphere and Fresnel zones for elevated antennas over a spherical earth, NBS Monograph 38.

Norton, K. A. (July-August 1959), System loss in radio wave propagation, J. Res. NBS 63D (Radio Prop.), No. 1, 53-73.

Schelkunoff, S. P., and H. T. Friis (1952), Antennas, theory, and practice, p. 446 (Wiley, New York, N.Y.).

Shinn, D. H. (1958), Polar diagram requirements for aerials for communication by ionospheric scatter, Proc. IEE 105 , Part B, Supplement No. 8, 45-52.

Smith, E. K。 (1959), Private communication. Williams, D. (1958), The structure of high-frequency ionospheric scatter signals, Proc. IEE 105, Part B, Supplement No.8, 19-26. 


\section{APPENDIX}

The relationship between signal generator calibration and the effective noise bandwidth [Koch, 1960] is obtained as follows:

1. Using a noise generator source of fairly high level, the receiver noise power output equals the product of the receiver integrated power gain over the pass band and the source noise power per unit bandwidth.

2. Using a signal generator source, the receiver power output equals the product of the power gain at the center of the pass band and the signal generator power.

3. If these two output powers are made equal a simple relation exists between the power gain at the center of the pass band and the integrated power gain. The effective noise bandwidth can then be readily calculated.

The effective noise bandwidth, $B$, is defined as the rectangular pass band which has the same maximum gain and passes the same noise power as the actual pass band.

$$
B=\frac{1}{G} \int G_{f} d f
$$

where $G$ = power gain at the center of the pass band

$$
G_{f}=\text { power gain as a function of frequency. }
$$

Using a noise generator source, the receiver noise power output is:

$$
P_{\text {out }}=(F+1) K T \int G_{f} d f
$$

where $F=$ noise figure reading of the noise generator. 
With a signal generator source tuned to the center of the pass band, and the signal generator output, $P_{s g}$, adjusted for the same receiver power output as before,

$$
P_{\text {out }}=P_{\text {sg }} \text {. }
$$

Then,

$$
P_{s g} G=(F+1) K T \int G_{f} d f
$$

and

$$
\frac{P}{(F+1) K T}=\frac{1}{G} \int G_{f} d f=B
$$

or

$$
10 \log _{10} \mathrm{~B}=10 \log _{10} P_{\mathrm{sg}}-10 \log _{10}(\mathrm{~F}+1) \mathrm{KT}
$$

which can be rewritten

$$
\begin{aligned}
10 \log _{10} \mathrm{~B}= & -10 \log _{10} \mathrm{KT}-10 \log _{10}(\mathrm{~F}+1) \\
& +10 \log _{10} \mathrm{P}_{\mathrm{sg}} .
\end{aligned}
$$

If the power is expressed in decibels above one watt (dbw) and the noise figure in terms of decibels above KTB,

$$
10 \log _{10} \mathrm{KT}=204 \mathrm{dbw} \text { with } \mathrm{B}=1 \mathrm{~Hz}
$$

when $\mathrm{T}=288.37^{\circ} \mathrm{K}$.

If we write

$$
N=10 \log _{10}(F+1) \text { expressed in db above KTB }
$$

and

$$
\mathrm{S}=10 \log _{10} \mathrm{P} \text { sg expressed in dbw }
$$

we obtain

$$
10 \log _{10} B=204-N+S
$$

or

$$
B=\text { Antilog }_{10} \frac{204-(N-S)}{10} \text {. }
$$

The value of $(\mathrm{N}-\mathrm{S})$ for each of the nominal bandwidths utilized was obtained by plotting a number of the noise calibrations against the corresponding signal calibrations. The corresponding effective noise bandwidths are given in Table VII. The values of $(N-S)$ for effective noise bandwidths of 100,1000 , and $2000 \mathrm{c} / \mathrm{s}$ are also given. 
Nominal 3-db bandwidths

$\mathrm{c} / \mathrm{s}$

40

80

250
$\underline{(N-S)}$

$\mathrm{db}$

$188 \pm 1$

$181 \pm 1$

$179 \pm 1$

184

174

171
Effective noise bandwidths

$$
\mathrm{c} / \mathrm{s}
$$

$40 \pm 10$

$200 \pm 50$

$315 \pm 80$ 100

1000

2000

The probable errors in bandwidth in Table VII correspond to the errors in the determination of $(N-S)$. The effective noise bandwidths probably differ from the nominal bandwidths because the $1000 \mathrm{c} / \mathrm{s}$ filters in the receivers which determined the bandwidths were broadened by increasing the filter circuit resistances, thus causing the skirts to widen rapidly.

The above expression can be rewritten in the form

$$
\mathrm{N}-\mathrm{S}=204-10 \log \mathrm{B} \text {. }
$$

This formula is a convenient means of converting the galactic noise levels, $N$, of figures 15 and 16 into equivalent signal levels, $S$, when the noise bandwidth is known. The galactic noise levels of figures 15 and 16 are representative of the levels obtained using longwire rhombic antennas pointed at the indicated declinations. See also section 3.4 . 


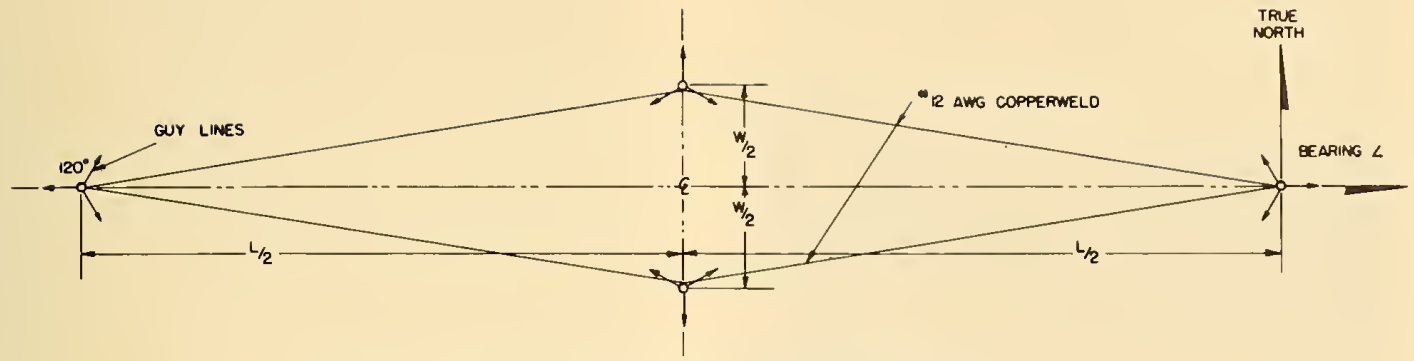

PLAN VIEW OF RHOMBIC ANTENNAS

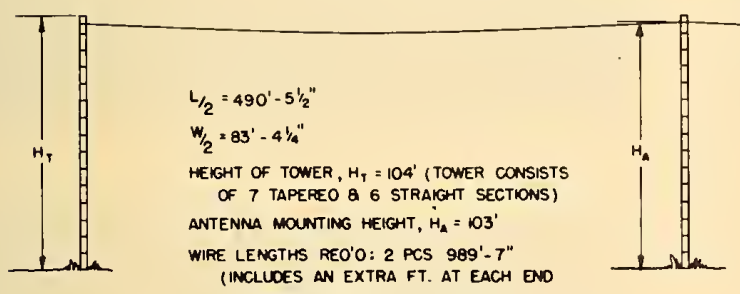

BEARING $\angle E$. OF TRUE NORTH:

FROM A TO $\theta-190^{\circ} 54^{\prime}$

FROM B TO A $-8^{\circ} 42^{\prime}$

FRESNEL ZONE OISTANCES, (FT):

$\frac{\text { NEAR }}{361} \quad \frac{\text { CENTER }}{2001} \quad \frac{\text { FAR }}{10170}$

(INCLUOES AN EXTRA FT. AT EACH ENY

TO MAKE CONNECTIONS AT APEX)

TOWER \& ANTENNA HEIGHTS FOR SEVILLE - WEYMOUTH PATH

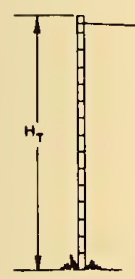

$L / 2=491^{\prime}-9^{\prime}$

$w / 2=74^{\prime}-9^{\prime \prime}$

HEICHT OF TOWER, $H_{T}=64^{\prime}$ ( TOWER CONSISTS

OF $\mathrm{O}$ TAPEREO SECTIONS)

ANTENNA MOUNTING HEIGHT, $H_{4}=63^{\circ}$

WRE LENGTHS REO'O: 2 PCS. 969'-7"

(INCLUOES AN EXTRA FT. AT EACH ENO

TO MAKE CONHECTIONS AT APEX)
BEARING $\angle E$. OF TRUE NORTH:

FROM C TO D - $165^{\circ} 54^{\prime}$

From 0 TO C - $340^{\circ} 0^{\circ}$

FRESNEL ZONE DASTANCES, (FT.):

$\frac{N E A R}{131} \quad \frac{\text { CENTER }}{755} \quad \frac{\text { FAR }}{4922}$

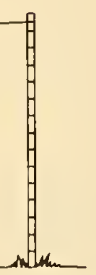

TOWER \& ANTENNA HEIGHTS FOR TRIPOLI-LEGHORN PATH

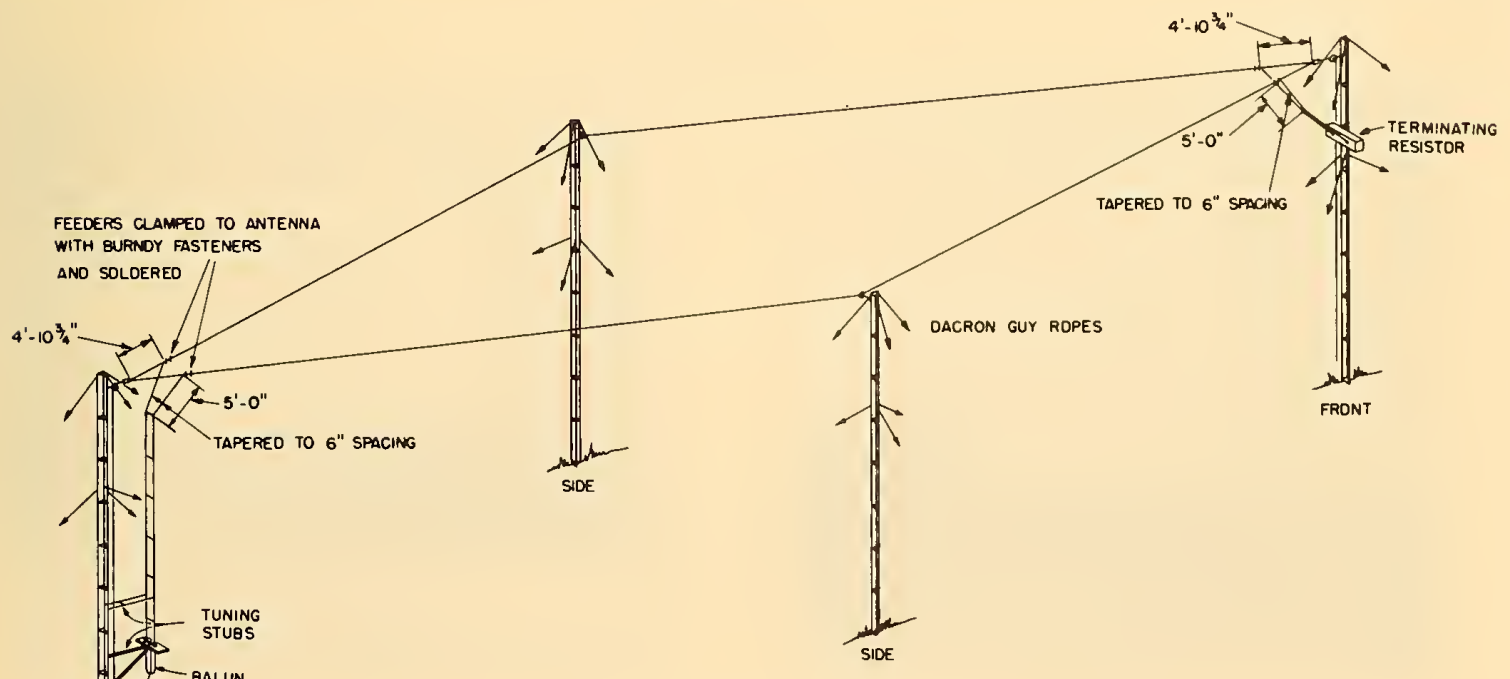

LONG WIRE RHOMBIC ANTENNA

Figure 1. Details of rhombic antennas 

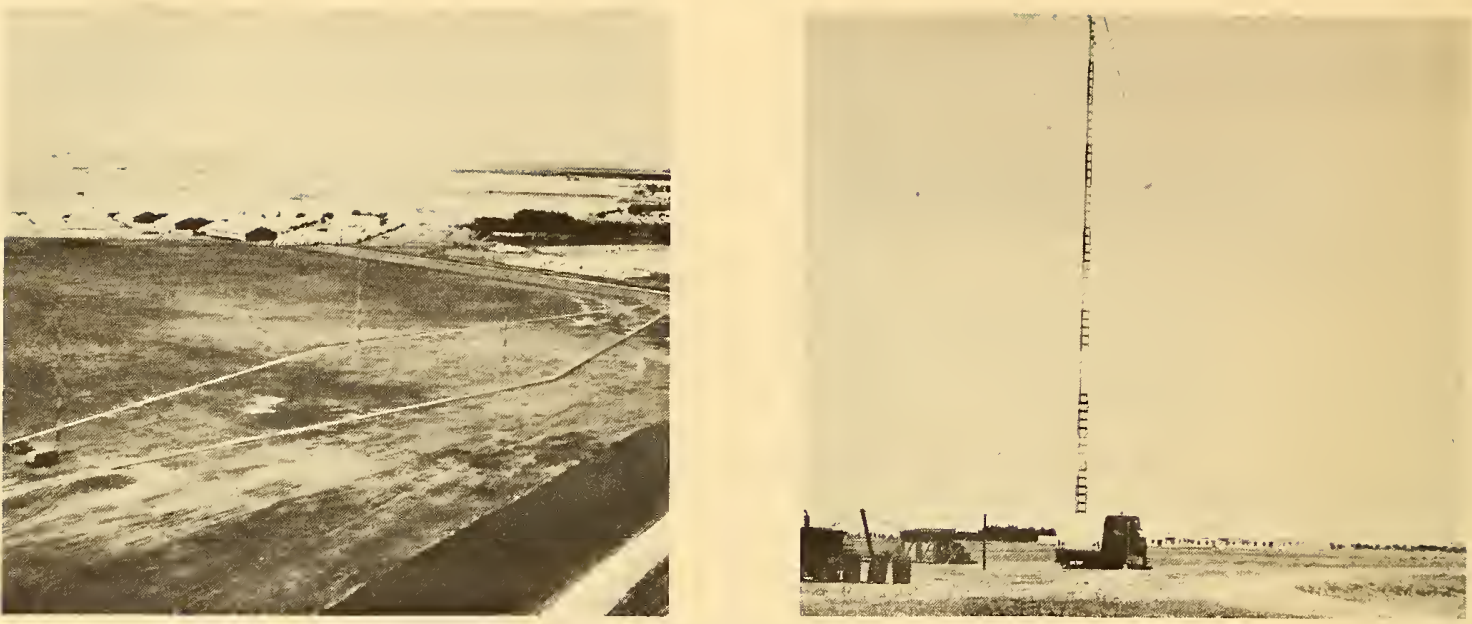

-WEYMOUTH SITE-
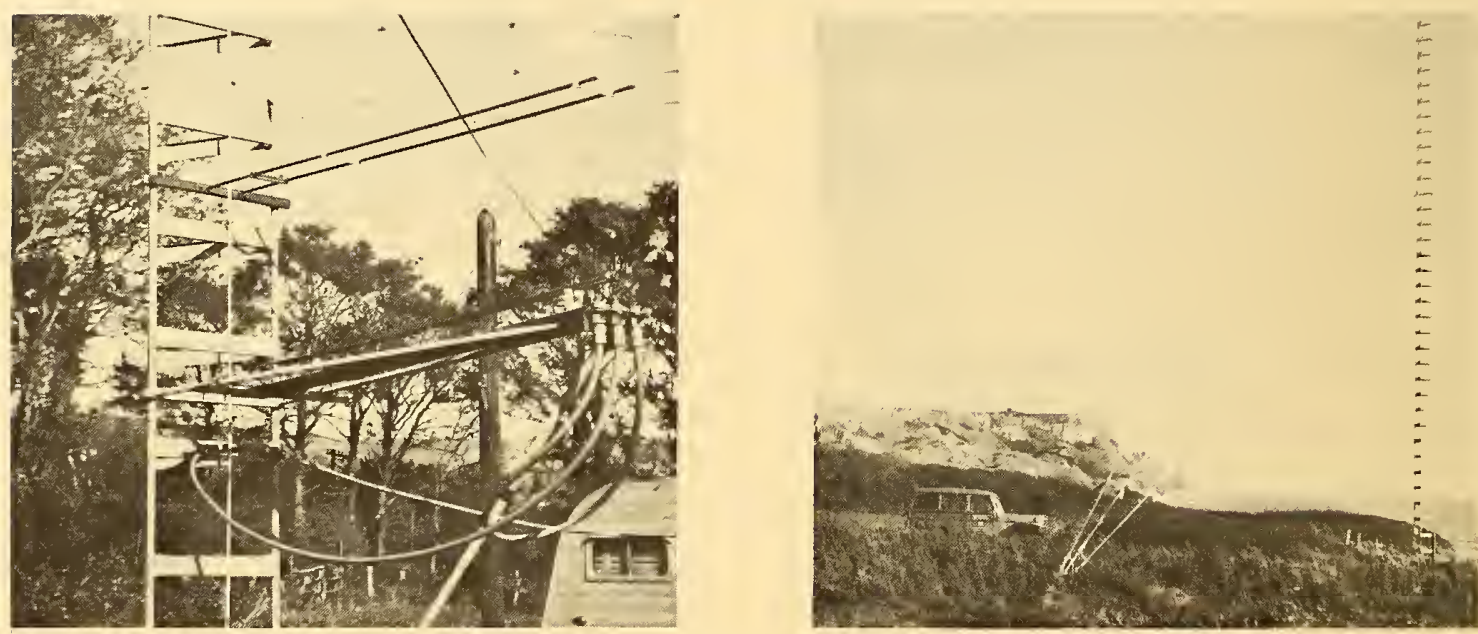

-TRIPOLI SITE-
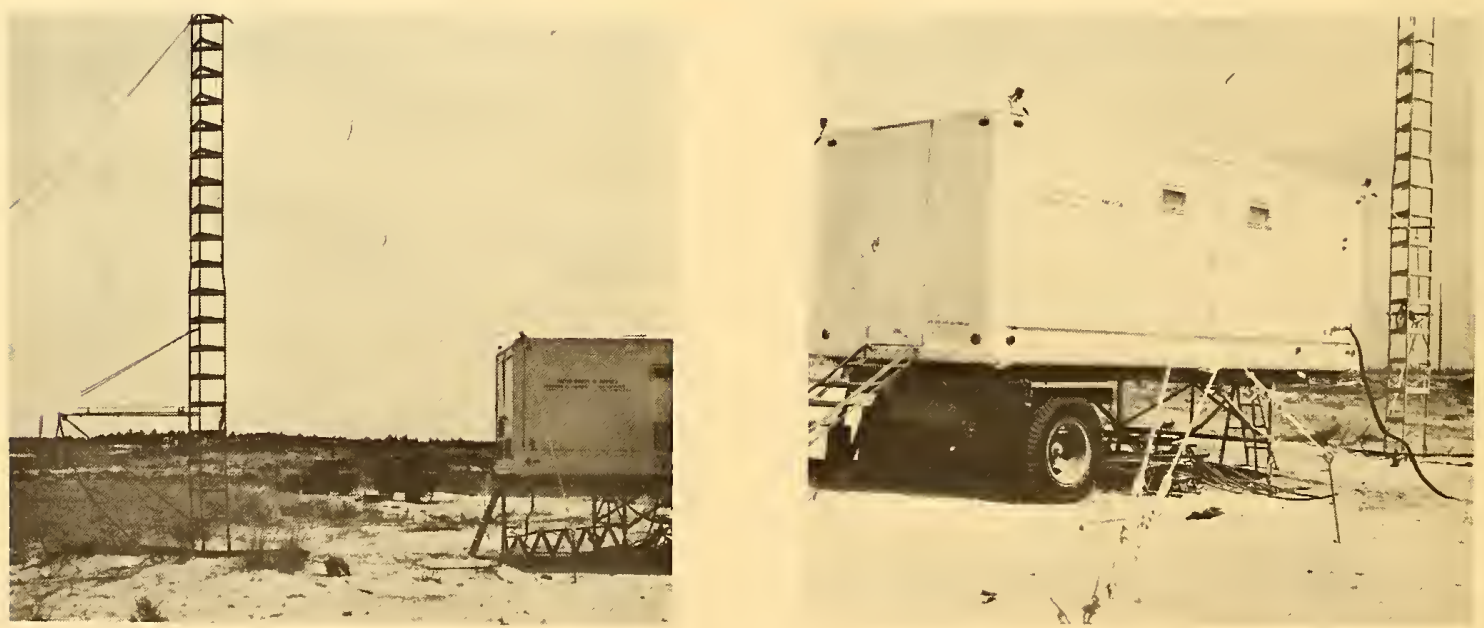

Figure 2. Photographs of sites 


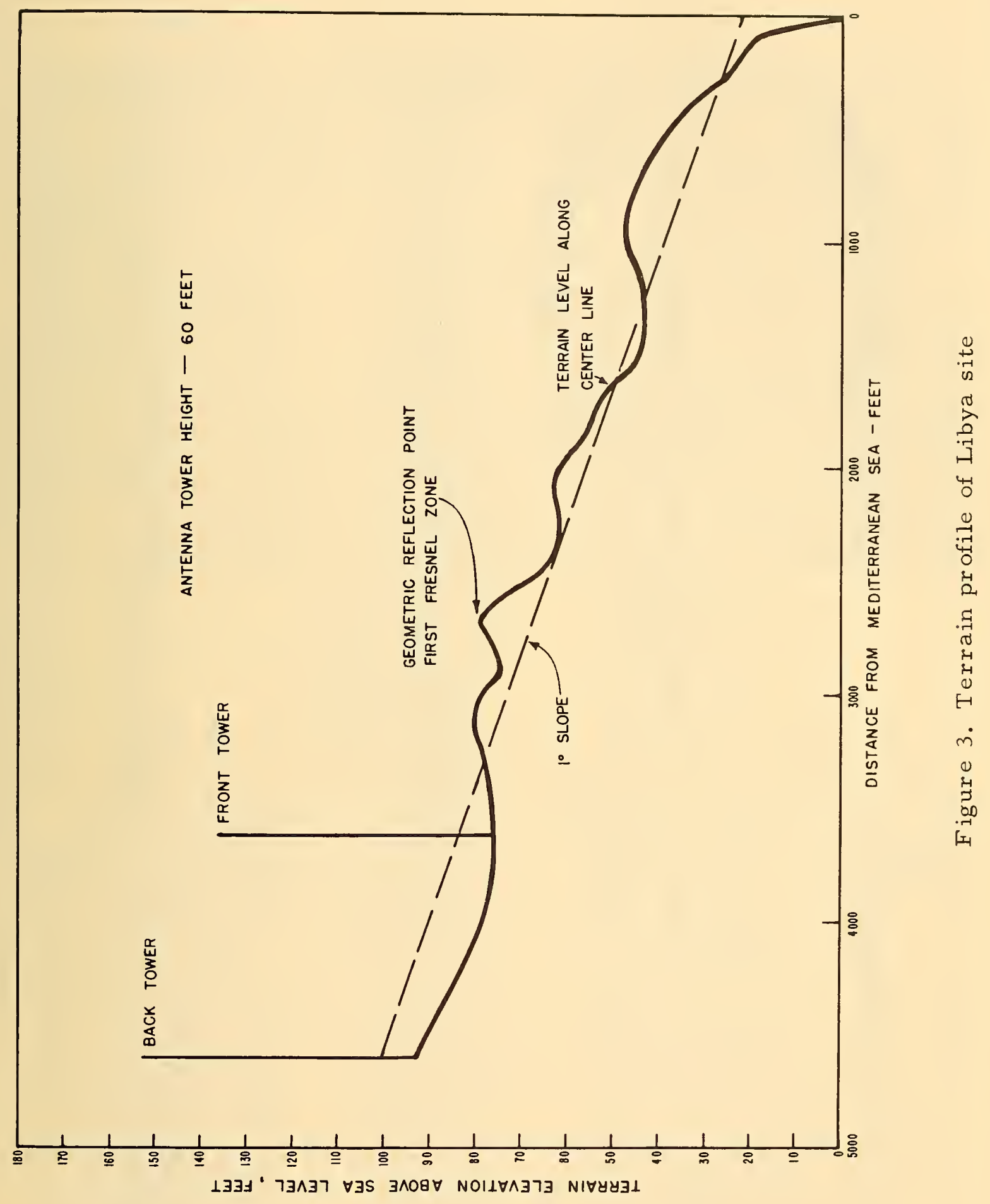




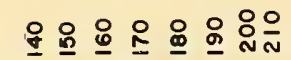

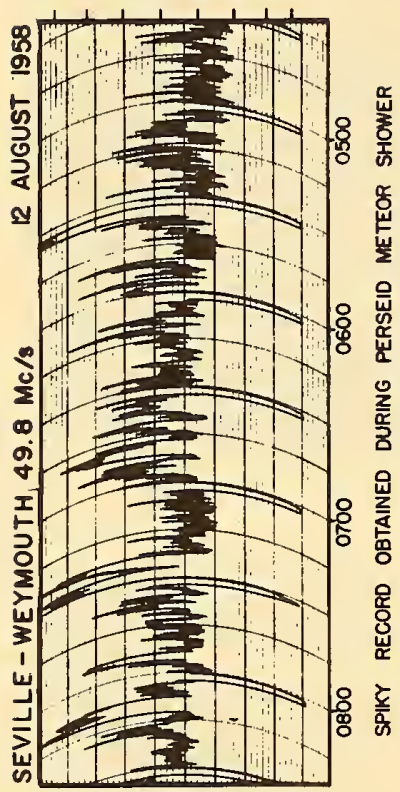

SS07 พ3LSAS

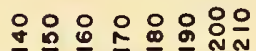

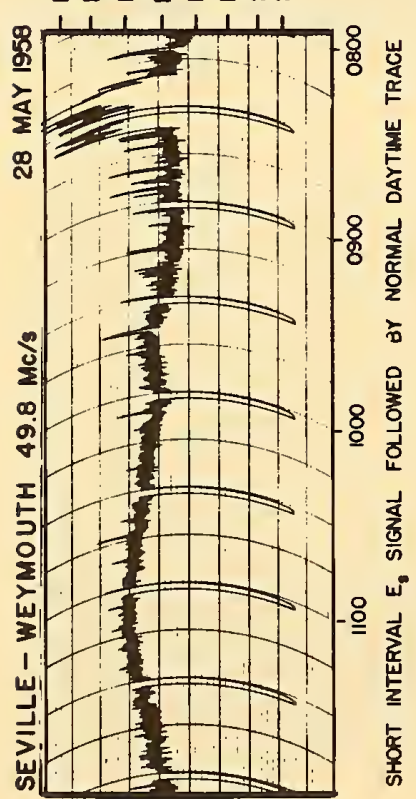

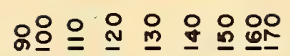

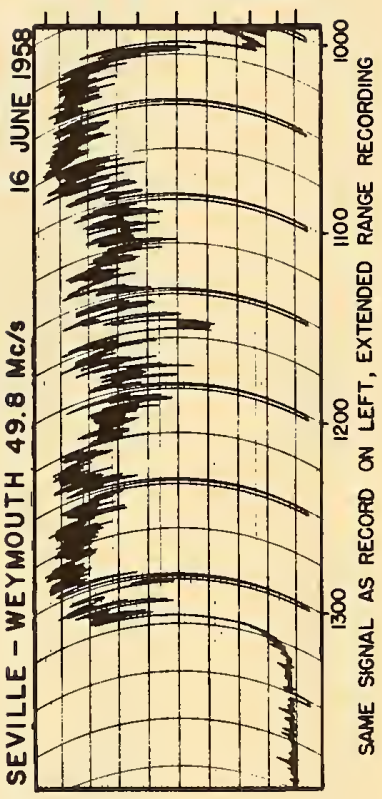

SSOา พ31SAS

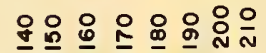

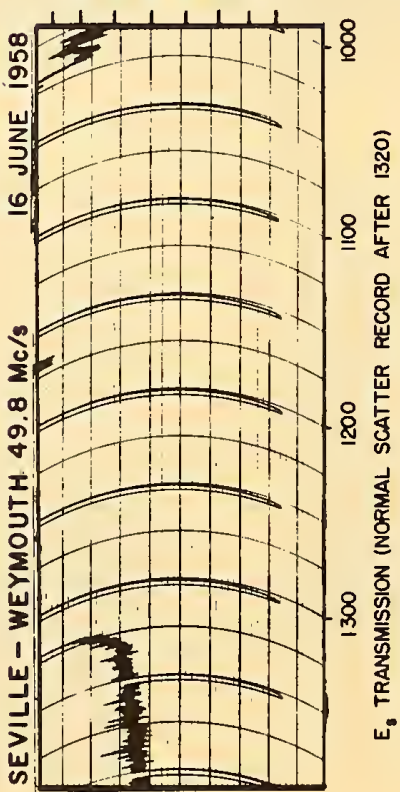

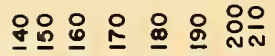

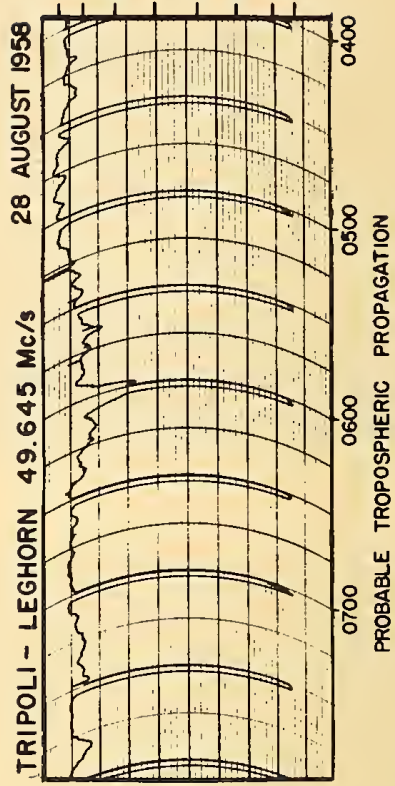

S507 พ31SᄉS

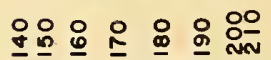

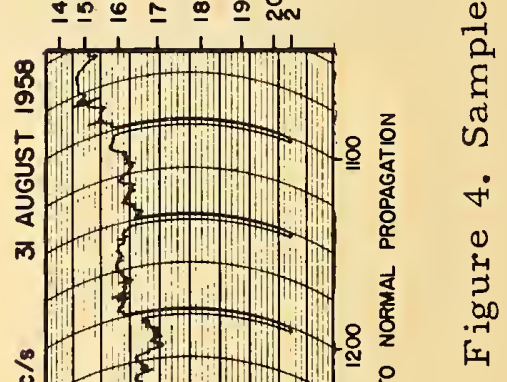


SSO7 WJ1SAS

웅으응으응응ㅇㅇ응
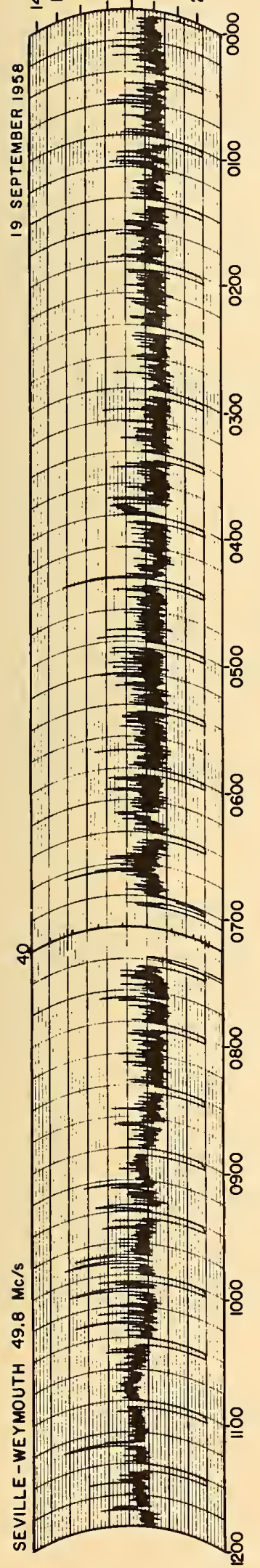

SSO7 WJ1SAS
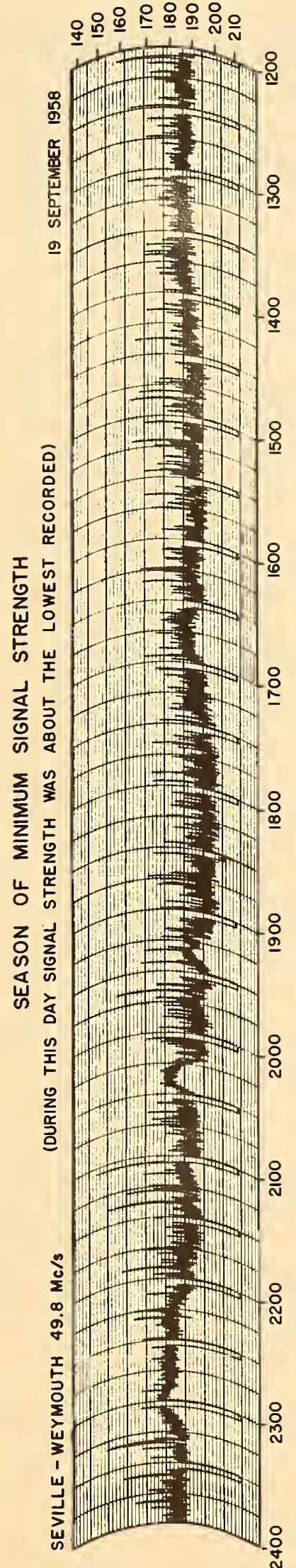

SSO7 WJ15גS

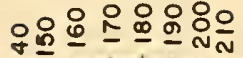

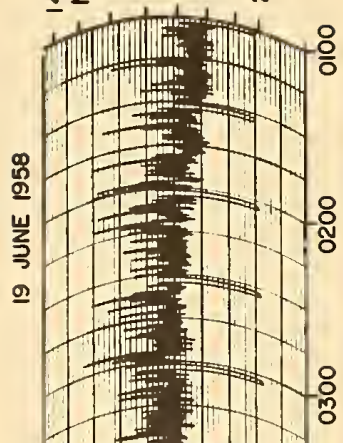

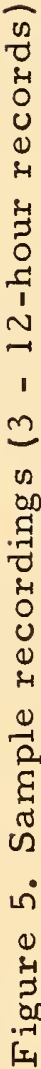


KEY TO SYMBOLS USED ON ALL DIURNAL VARIATION FIGURES

- 0 SYSTEM LOSS EXCEEDED $90 \%$ OF THE TIME INCLUDING SIGNALS PROPAGATED VIA THE SPORADIC - E LAYER

$\triangle \longrightarrow \triangle$ AS ABOVE BUT EXCLUDING ES PROPAGATED SIGNALS

- SYSTEM LOSS EXCEEDED $50 \%$ OF THE TIME INCL. ES - $\square$ SYSTEM LOSS EXCEEDED $50 \%$ OF THE TIME NOT INCL. $E_{S}$

$\nabla-\nabla-\nabla$ SYSTEM LOSS EXCEEDED $10 \%$ OF THE TIME

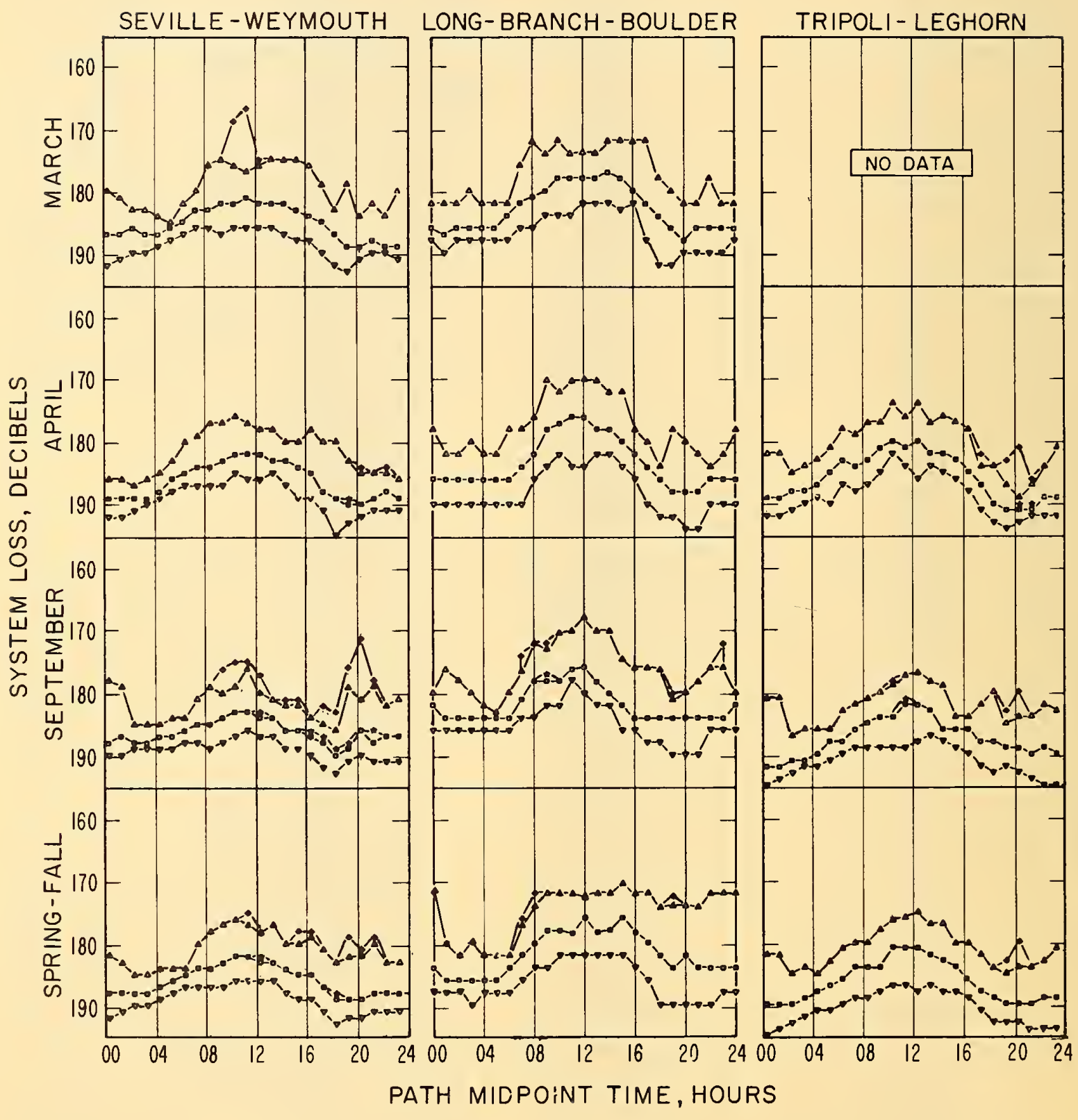

Figure 6. Diurnal variation during spring-fall months 


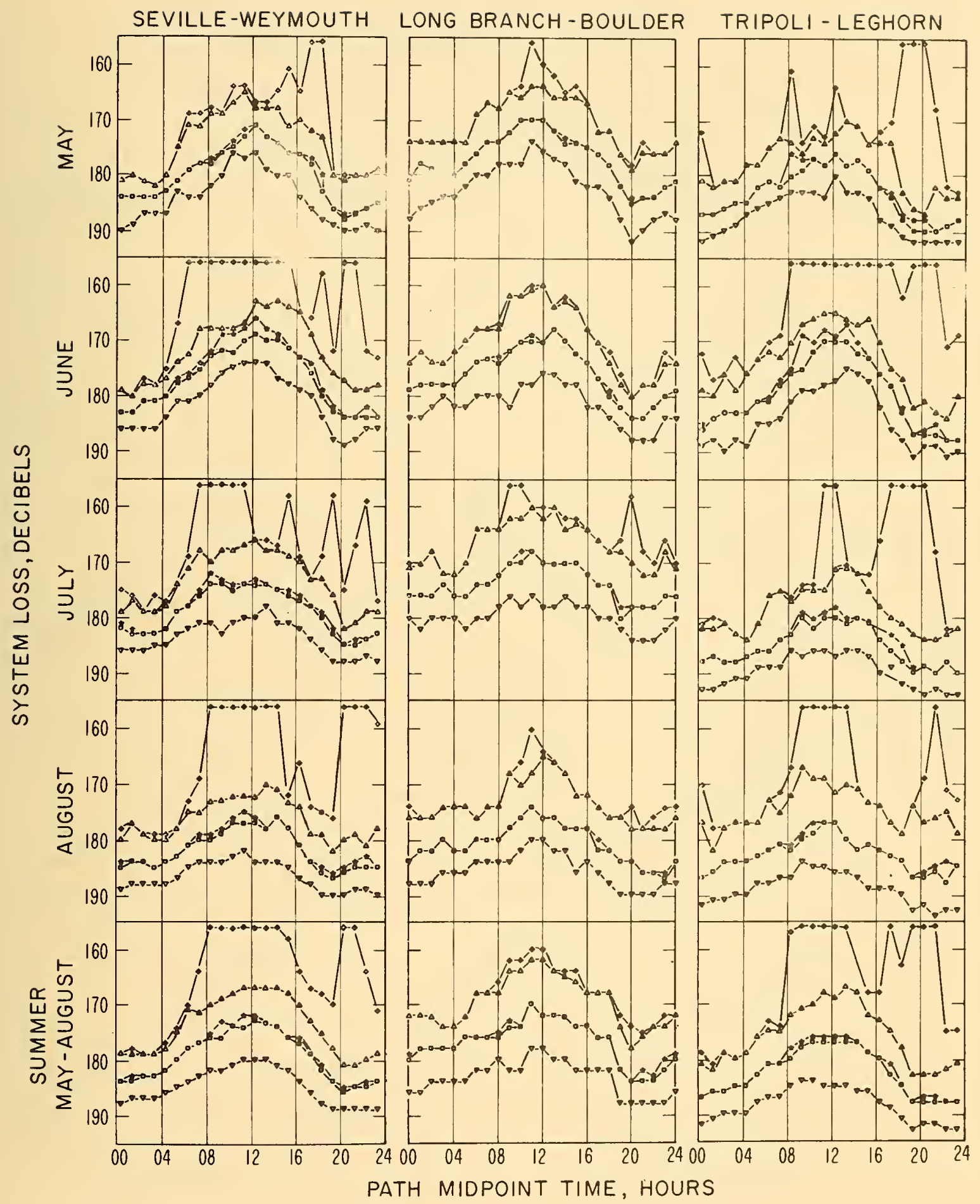

Figure 7. Diurnal variation during summer months 
KEY TO SYMBOLS USED ON CUMULATIVE DISTRIBUTION FIGURES 0 INCLUDES TROPOS PHERICALLY PROPAGATED SIGNALS 廿 \# INCLUDES SPORADIC-E PROPAGATED SIGNALS - 0 - IONOSPHERIC SCATTER SIGNALS ONLY

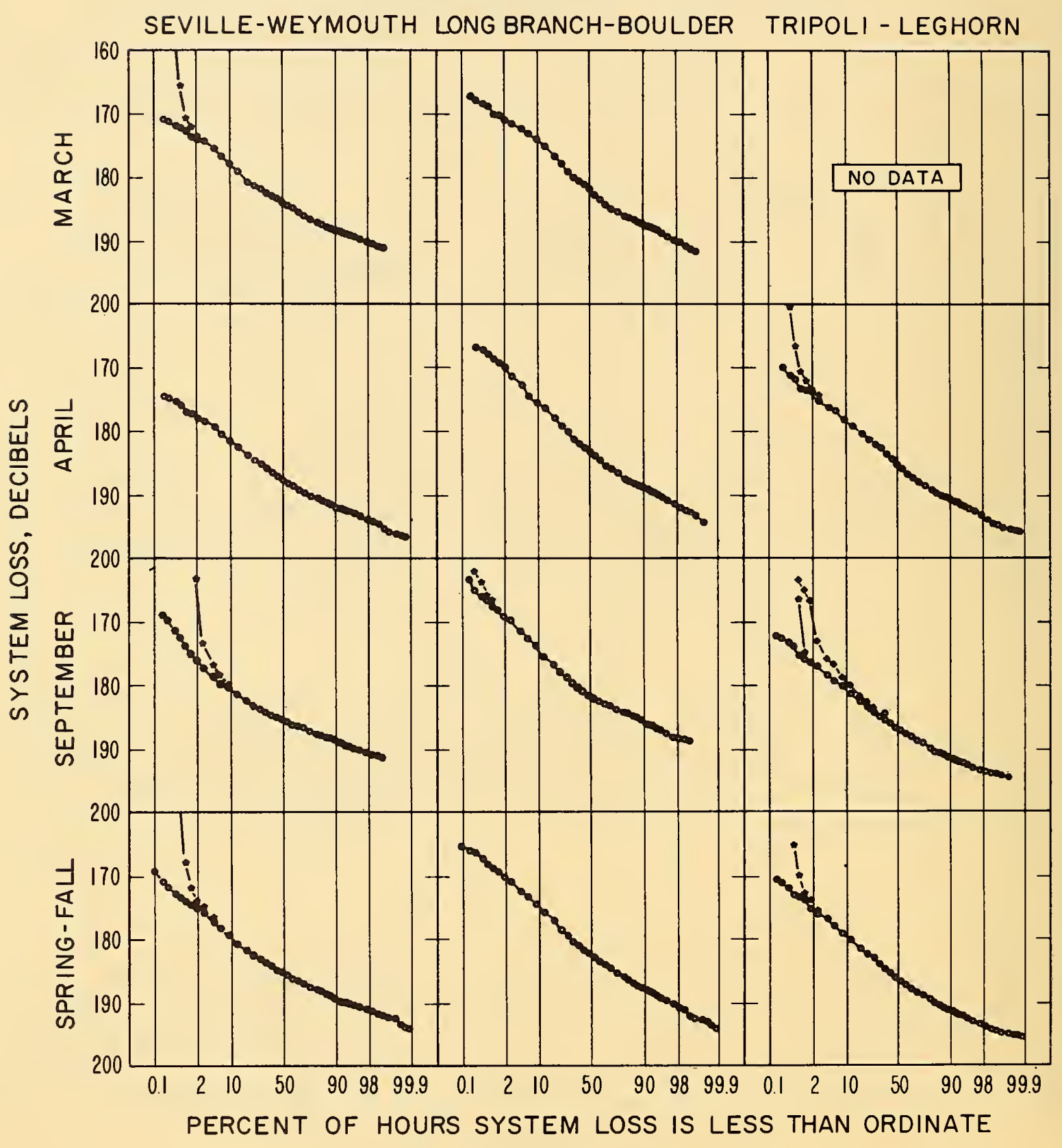

Figure 8. Cumulative distribution for spring-fall months 


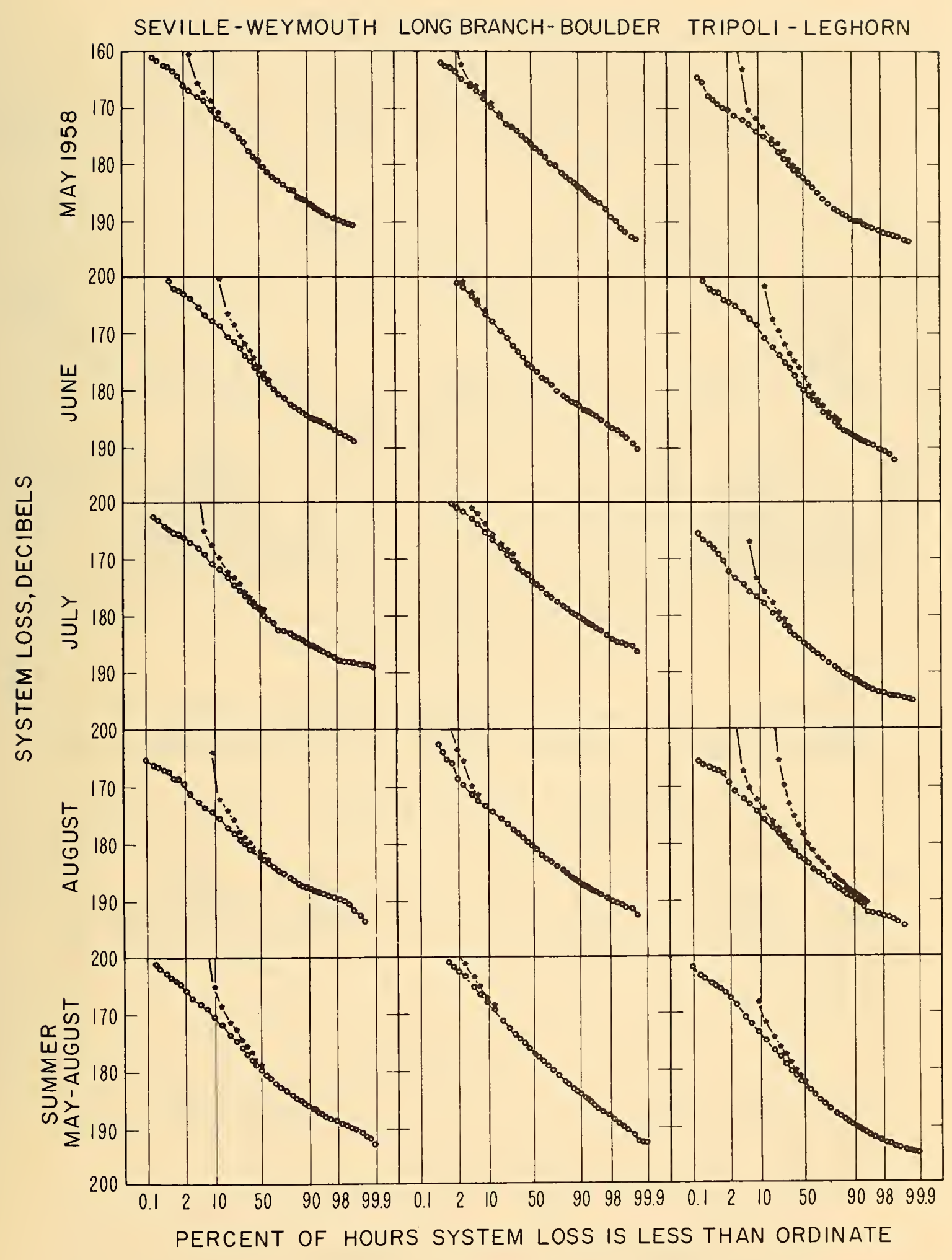

Figure 9. Cumulative distribution for summer months 


\section{KEY TO SYMBOLS ON THIS FIGURE \\ 口- - $\square$ MEDIAN SIGNAL LEVELS \\ - - 0 SIGNAL LEVELS EXCEEDED $90 \%$ OF THE TIME}

LONG BRANCH-BOULDER LONG BRANCH - BOULDER SEVILLE -WEYMOUTH
EXCEEDS SEVILLE-WEYMOUTH EXCEEDS TRIPOLI-LEGHORN EXCEEDS TRIPOLI-LEGHORN
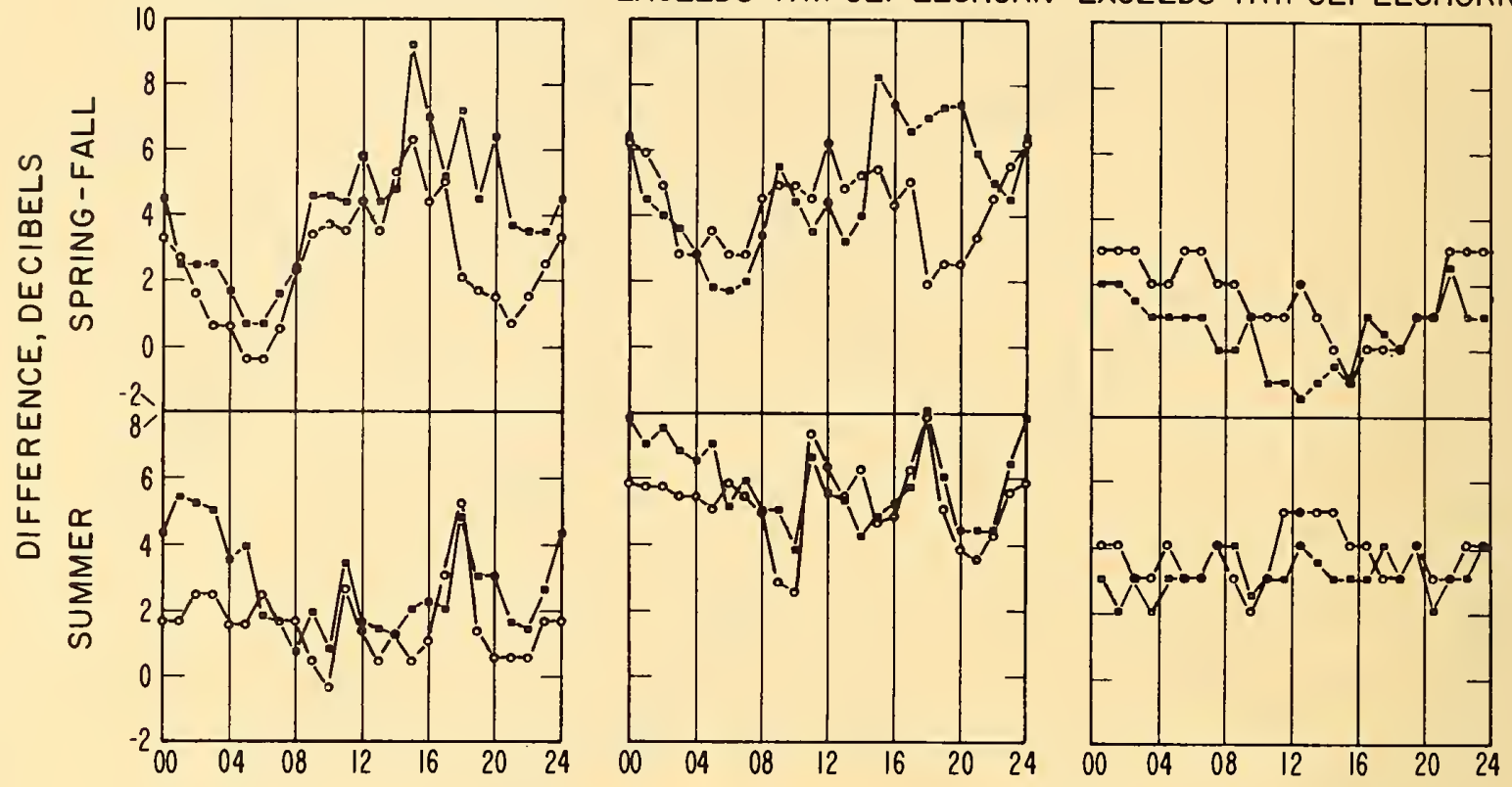

PATH MIDPOINT TIME, HOURS

KEY TO SYMBOLS ON THIS FIGURE

$\leadsto E_{S}$ PROPAGTION INCLUDED

$\longrightarrow$ SCATTER SIGNAL ONLY

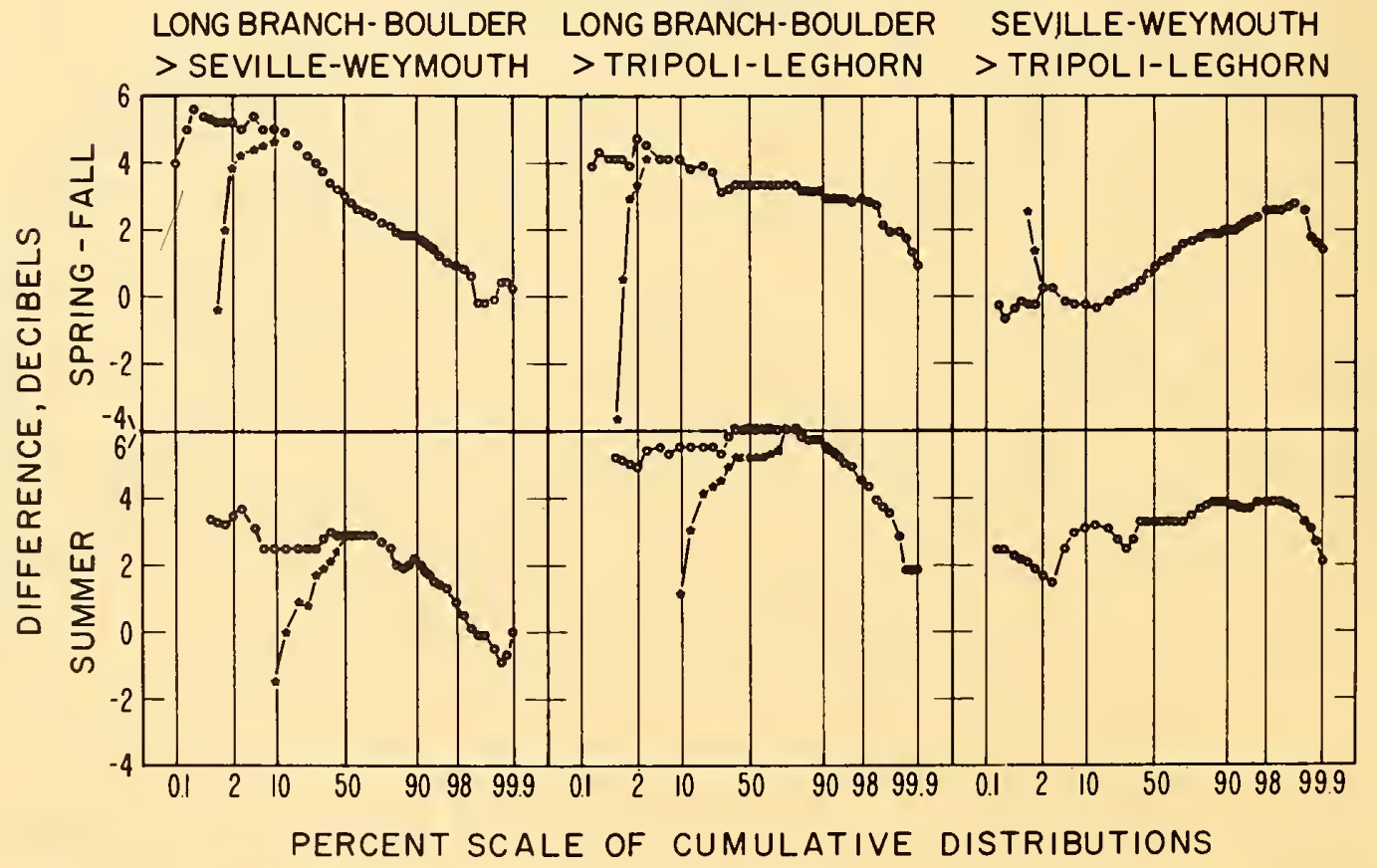

Figure 10. Differences between observed system losses (3 paths for summer months and spring-fall) 


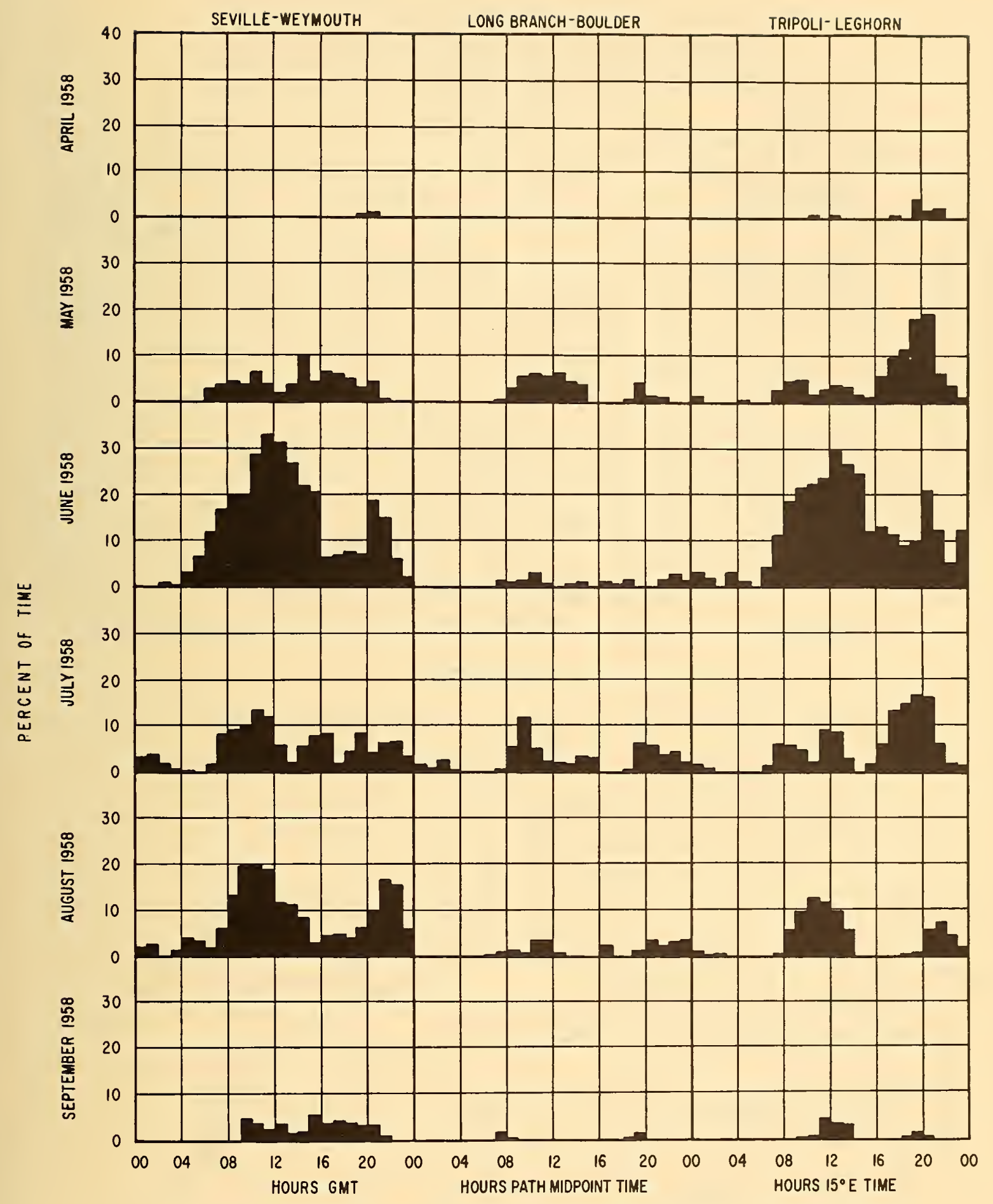

PERCENT OF TIME SYSTEM LOSS FOR SPORADIC-E PROPAGATED SIGNALS IS LESS THAN 156 DB

Figure 11. Percent of time sporadic-E propagated signal was present 
KEY TO SYMBOLS ON THIS FIGURE

$\Delta-\Delta$

SYSTEM LOSS EXCEEDED $90 \%$ OF THE TIME

D SYSTEM LOSS EXCEEDED $50 \%$ OF THE TIME

$\nabla$ SYSTEM LOSS EXCEEDED $10 \%$ OF THE TIME
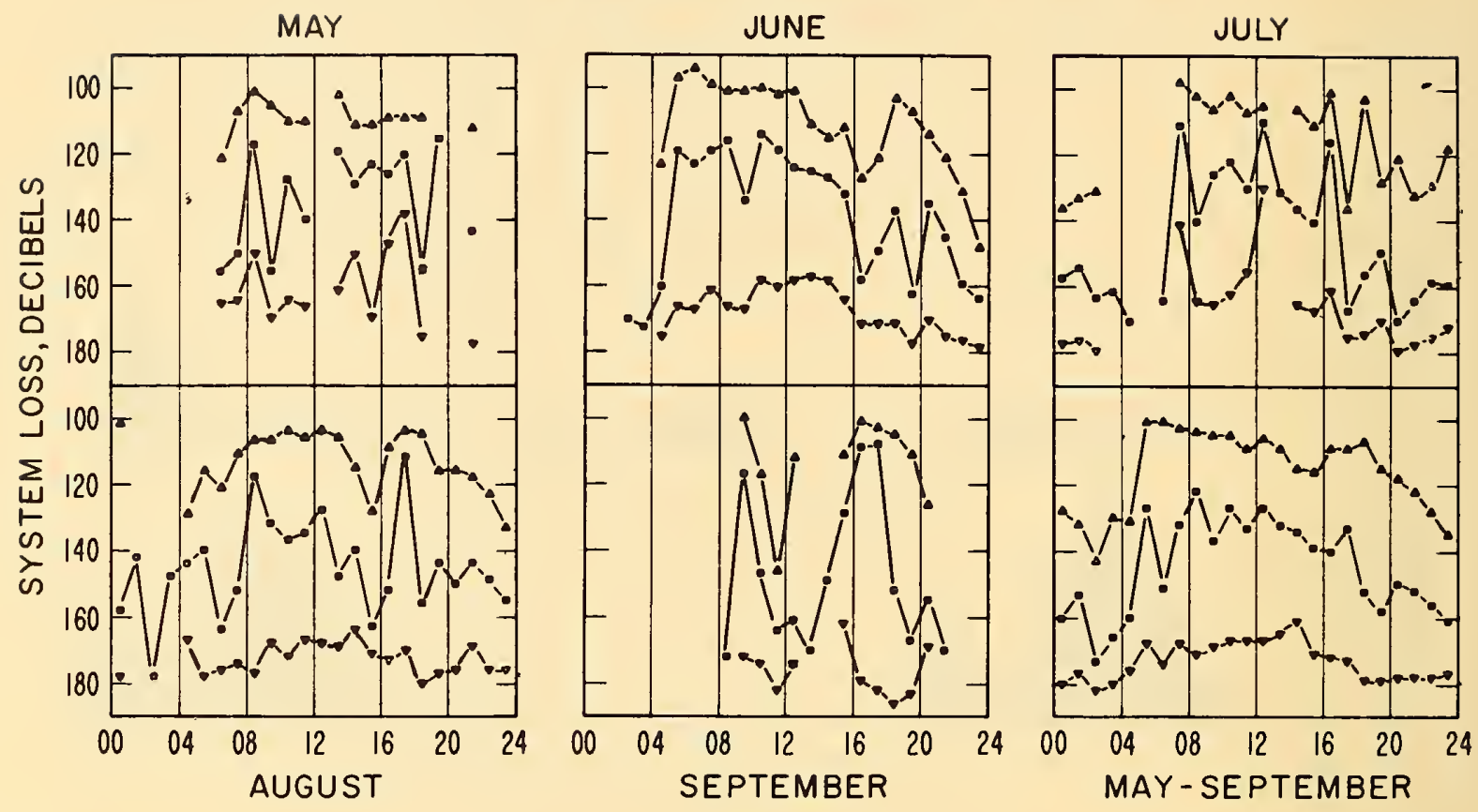

$O^{\circ}$ TIME

Figure 12. Diurnal variation of sporadic-E signals at Weymouth

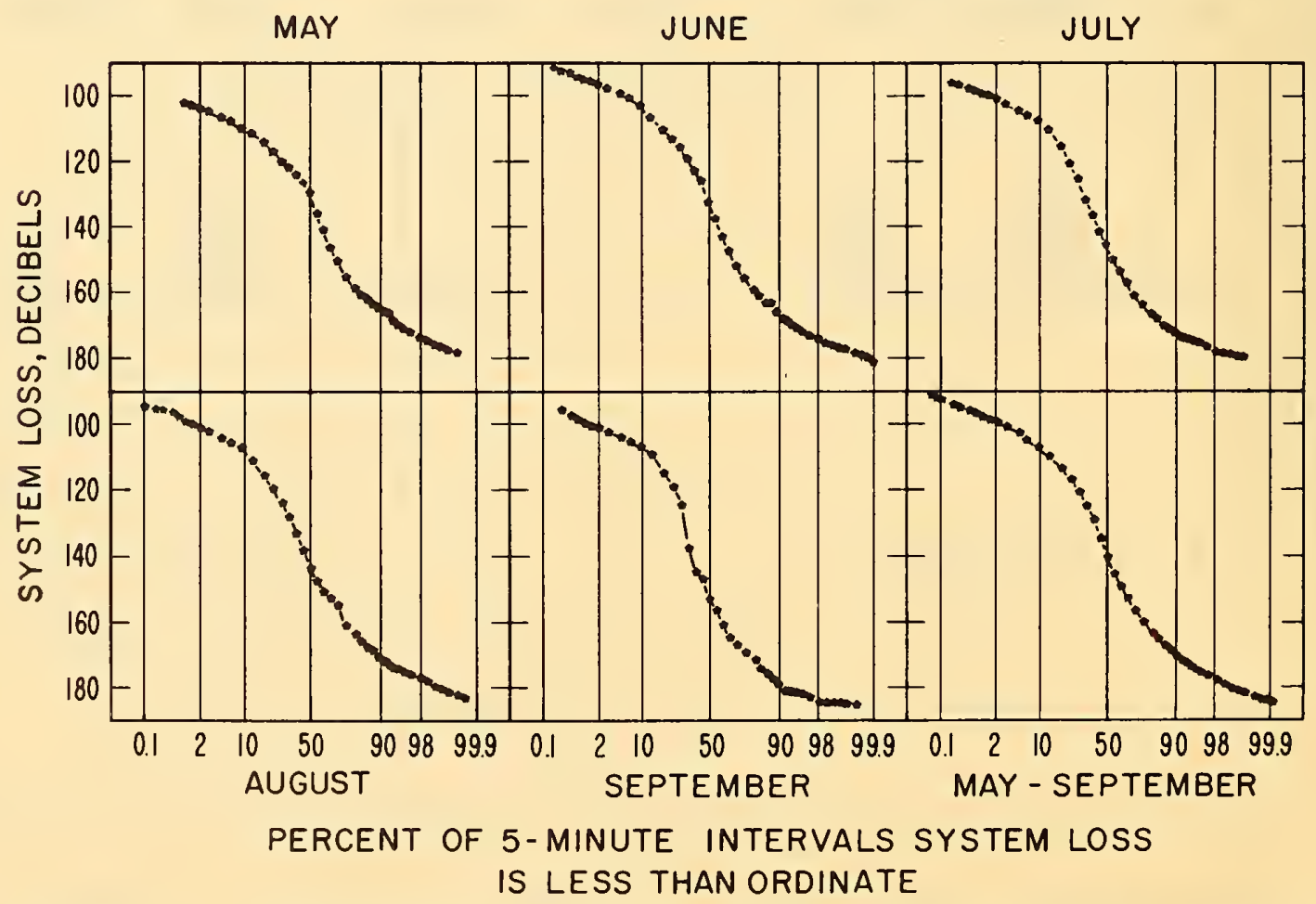

Figure 13. Cumulative distribution of sporadic-E signals at Weymouth 
- mean value less than plotted point

- interpolated value
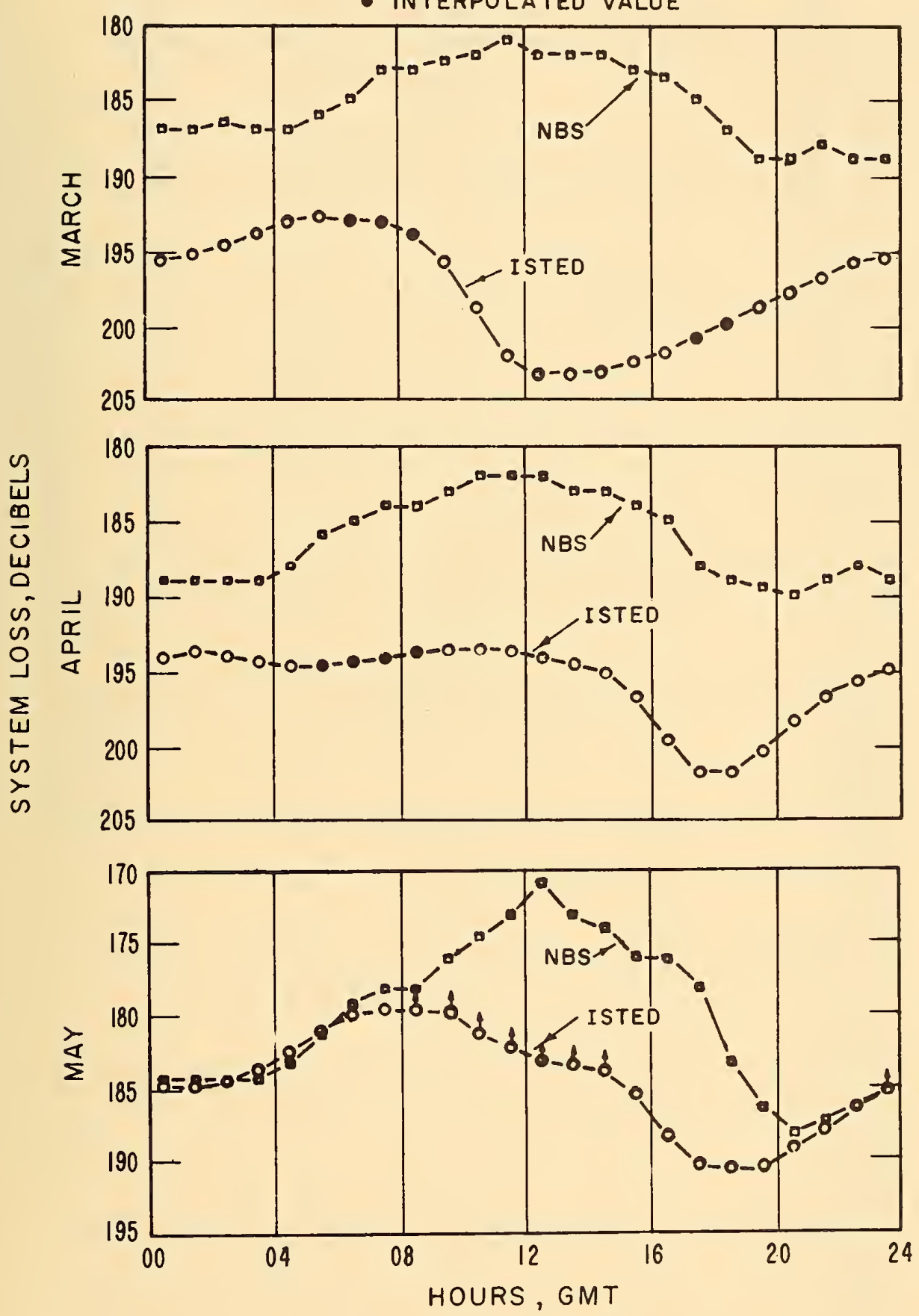

Figure 14. Comparison with Isted 1955 results 


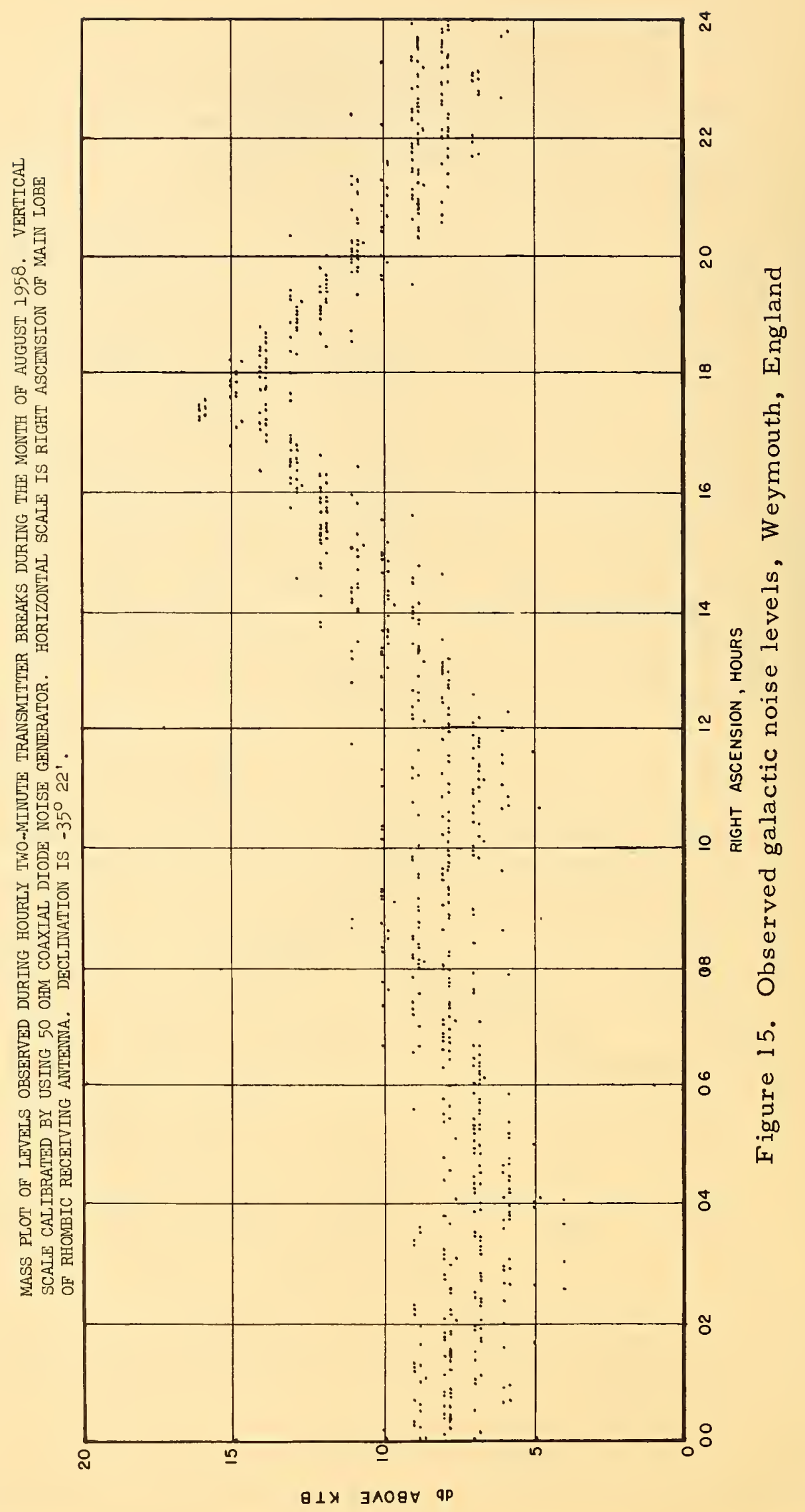




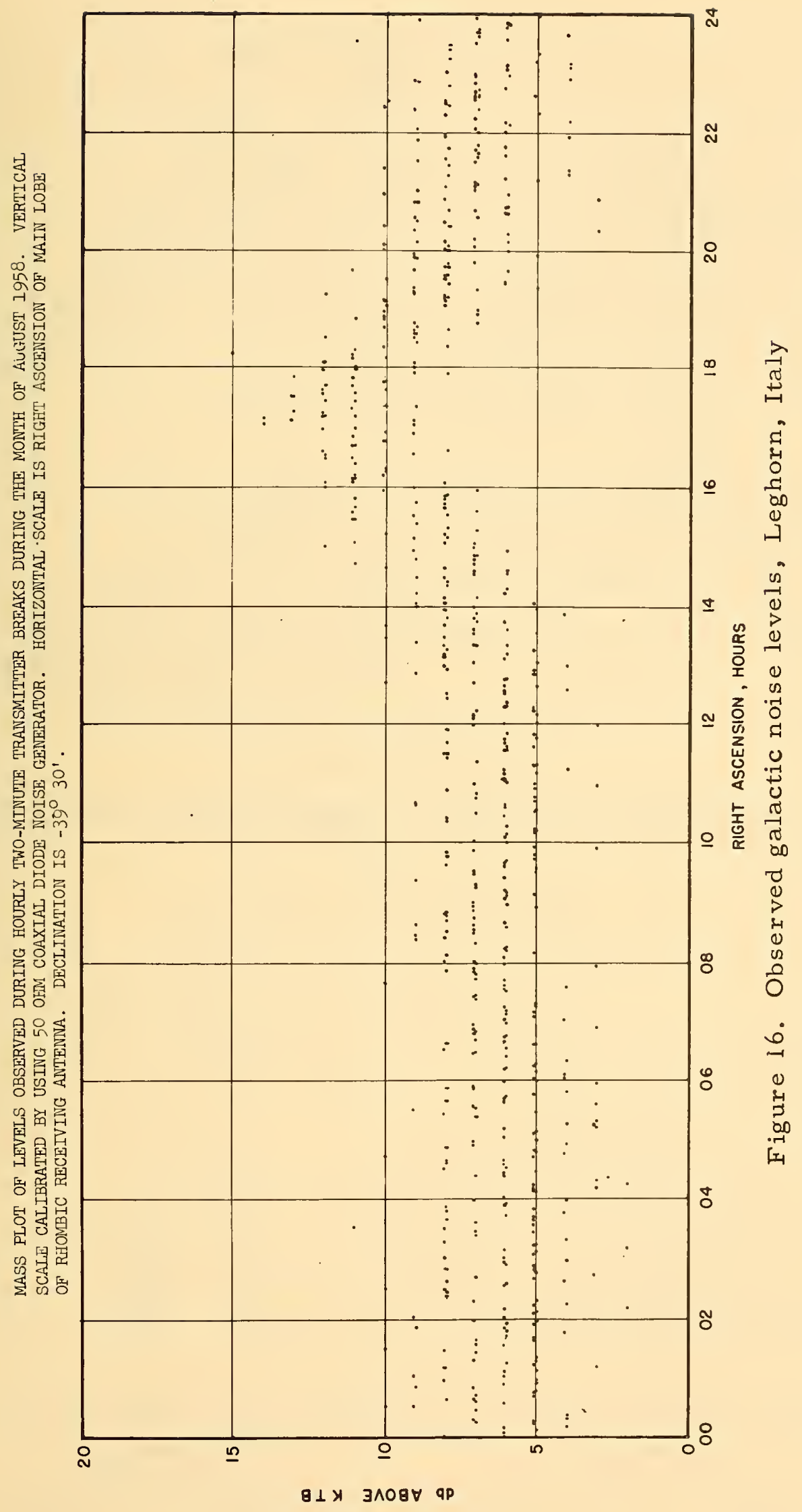



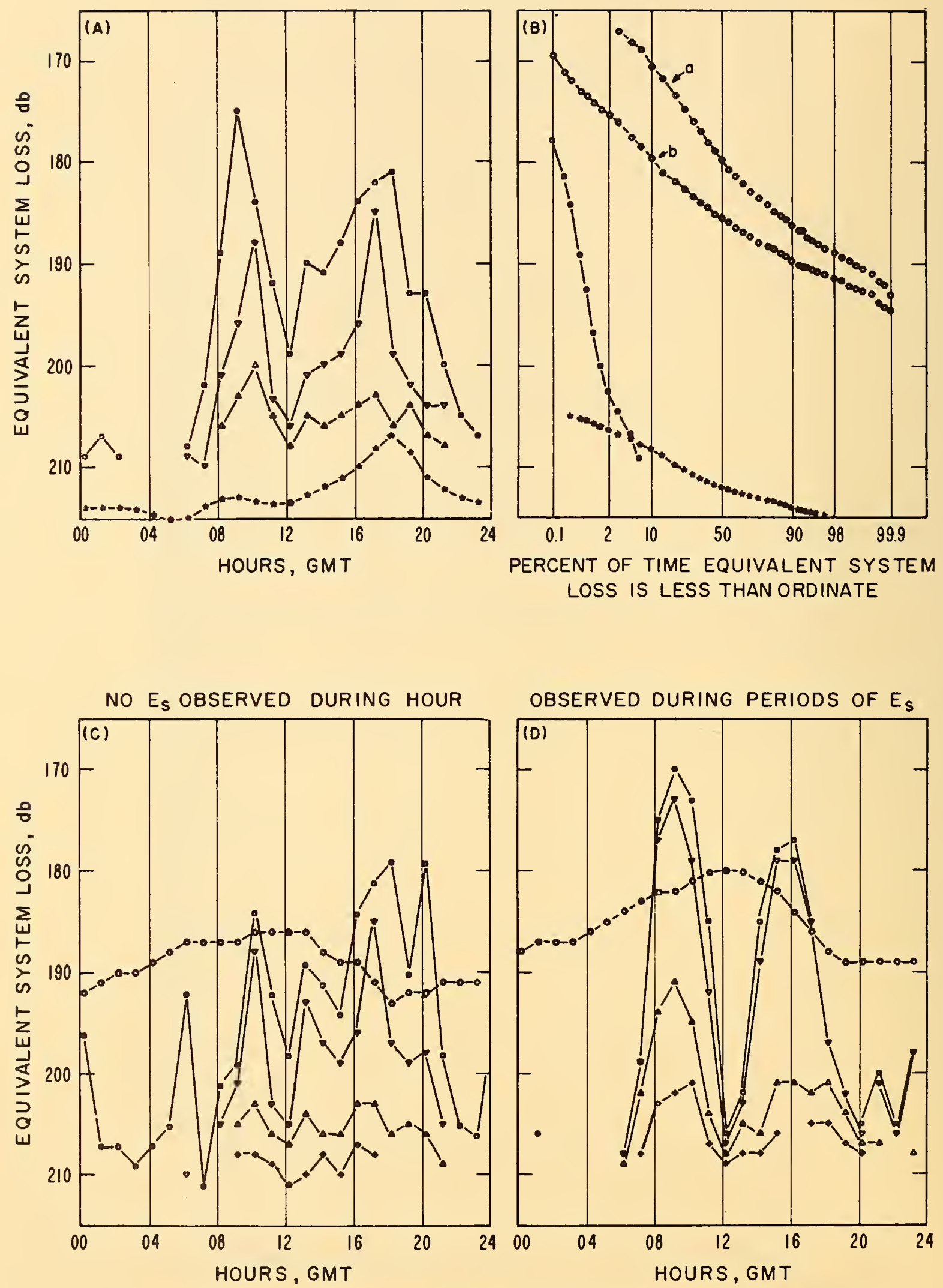

Figure 17. Interference observed at Weymouth, England 
A.

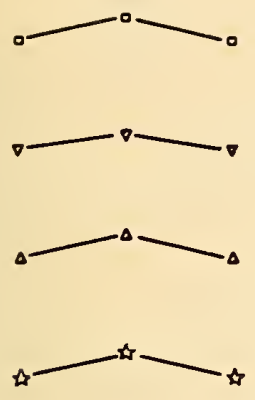

PEAK INTERFERENCE LEVEL EXCEEDED DURING $1 \%$ OF TRANSMITTER BREAKS (BOTH CLASSES)

PEAK INTERFERENCE LEVEL EXCEEDED DURING $2 \%$ OF TRANSMITTER BREAKS (BOTH CLASSES)

PEAK INTERFERENCE LEVEL EXCEEDED DURING $5 \%$ OF TRANSMITTER BREAKS (BOTH CLASSES)

gALACTIC NOISE EXCEEDED $10 \%$ OF THE TIME. DIURNAL CURVE FOR SEPTEMBER 30.

B.

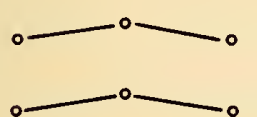

(a) IONOSPHERIC SCATTER SIGNAL (SUMMER 1958)

(b) IONOSPHERIC SCATTER SIGNAL (SPRING - FALL 1958)

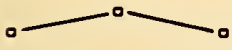

PEAK INTERFERENCE LEVEL (BOTH CLASSES)

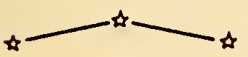

galactic noIse leVel

C.

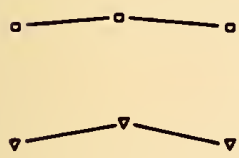

HIGHEST INTERFERENCE LEVEL OBSERVED DURING ANY TRANSMITTER BREAK

PEAK INTERFERENCE LEVEL EXCEEDED DURING $2 \%$ OF TRANSMITTER BREAKS

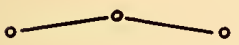

IONOSPHERIC SCATTER SYSTEM LOSS EXCEEDED $10 \%$ OF THE TIME (SPRING-FALL 1958)

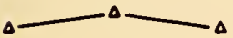

PEAK INTERFERENCE LEVEL EXCEEDED DURING $5 \%$ OF TRANSMITTER BREAKS

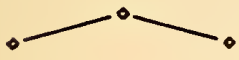

PEAK INTERFERENCE LEVEL EXCEEDED DURING $10 \%$ OF TRANSMITTER SREAKS

D.

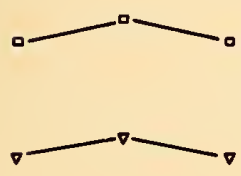

HIGHEST INTERFERENCE LEVEL OBSERVED DURING ANY TRANSMITTER BREAK

PEAK INTERFERENCE LEVEL EXCEEDED DURING $2 \%$ OF TRANSMITTER BREAKS

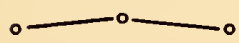

IONOSPHERIC SCATTER SYSTEM LOSS EXCEEDED 10\% OF THE TIME (SUMMER 1958)

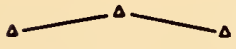

PEAK INTERFERENCE LEVEL EXCEEDED DURING $5 \%$ OF TRANSMITTER BREAKS

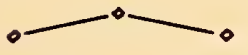

PEAK INTERFERENCE LEVEL EXCEEDED DURING $10 \%$ OF TRANSMITTER BREAKS 
TABLE ZI

(OATA FOR FIGURE 6)

PATH FREQUENCY TIME CORRECTION

SEVILLE-WEYMOUTH

$49.800 \mathrm{Mc} / \mathrm{s}$

14 MINUTES

SEVILLE - WEYMOUTH 49. $800 \mathrm{Mc} / \mathrm{s}$ 14 MINUTES

SEVILLE - WEYMOUTH 49.600 Mc/s 14 MINUTES

SEVILLE - WE YMOUTH 49. $800 \mathrm{Mc} / \mathrm{s}$ 14 MINUTES

LONG BRANCH-BOULDER 49. $8 B 0 \mathrm{Mc} / \mathrm{s}$ O MINUTES

LONG BRANCH-BOULDER 49. $880 \mathrm{Mc} / \mathrm{s}$ O MINUTES

LONG BRANCH-BOULDER 49. $880 \mathrm{Mc} / \mathrm{s}$ 49.8BO Mc/s

LONG BRANCH-BOULDER 49. $880 \mathrm{Mc} / \mathrm{s}$ O MINUTES

\section{SYSTEM LOSS - SPRING-FALL MONTHS}

YEAR
MONTH TYPE

$195890 \% \mathrm{E}_{\text {s }}$

MARCH

$90 \%$ $50 \% E_{\text {s }}$

$50 \%$

$10 \%$

1958

APRIL

$90 \% \mathrm{E}_{\mathrm{s}}$ $90 \%$ $50 \% \mathrm{E}_{\mathrm{s}}$

$50 \%$ $10 \%$

$1958 \quad 90 \% E_{s}$ SEPTEMBER $90 \%$

$50 \% \mathrm{E}_{s}$ $50 \%$ $10 \%$

$1958 \quad 90 \% E_{\text {, }}$ SPRING-FALL $90 \%$ $50 \% E_{s}$ $50 \%$ $10 \%$ $1958 \quad 90 \% E_{s}$ MARCH $90 \%$ $50 \% \mathrm{E}_{3}$

$50 \%$

$10 \%$

$1958 \quad 90 \% \mathrm{Es}_{\text {s }}$ APRIL $90 \%$

$50 \% E_{s}$ $50 \%$ $10 \%$

$1958 \quad 90 \% E_{s}$ SEPTEMBER $90 \%$ $50 \% E_{5}$ $50 \%$ $10 \%$

$1958 \quad 90 \% \mathrm{E}_{3}$ SPRING-FALL $90 \%$ $50 \% E_{s}$ $50 \%$ $10 \%$
TIME IN HOURS

$\begin{array}{llllllllllllllllllllllll}0 & \text { ol } & 02 & 03 & 04 & 05 & 06 & 07 & 08 & 09 & 10 & 11 & 12 & 13 & 14 & 15 & 16 & 17 & 18 & 19 & 20 & 21 & 22 & 23\end{array}$

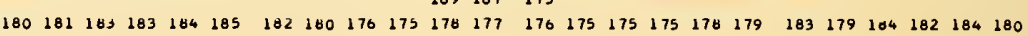
$\begin{array}{llllllllllllllllllllllll}187 & 187 & 186 & 147 & 107 & 184 & 185 & 183 & 183 & 182 & 182 & 181 & 182 & 182 & 182 & 183 & 184 & 185 & 167 & 189 & 189 & 188 & 189 & 189\end{array}$

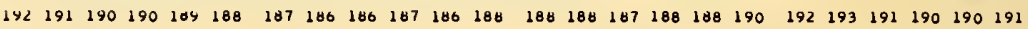

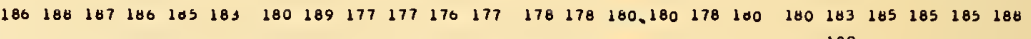
189

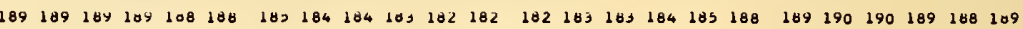

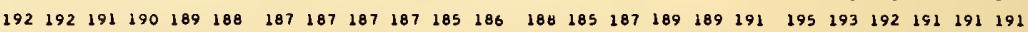
$\begin{array}{llllllllllll}176 & 175 & 175 & 177 & 181 & 181 & 182 & 103 & 178 & 171 & 178\end{array}$ $\begin{array}{llllllllllllllllllllllll}178 & 179 & 185 & 185 & 185 & 184 & 184 & 181 & 179 & 180 & 179 & 176 & 180 & 181 & 186 & 182 & 184 & 185 & 188 & 179 & 161 & 179 & 182 & 181 .\end{array}$

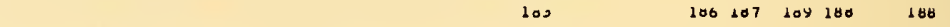
$\begin{array}{lllllllllllllllllllllllll}188 & 187 & 164 & 108 & 107 & 187 & 186 & 185 & 185 & 184 & 163 & 163 & 184 & 184 & 186 & 186 & 187 & 188 & 190 & 189 & 180 & 188 & 187 & 187\end{array}$ $\begin{array}{lllllllllllllllllllllllllll}190 & 190 & 184 & 189 & 109 & 189 & 188 & 188 & 189 & 188 & 187 & 188 & 187 & 187 & 189 & 189 & 190 & 192 & 193 & 191 & 190 & 191 & 191 & 191\end{array}$ \begin{tabular}{lllllll}
\hline 175 & 178 & 178 & 178 & $179 \quad 101$ & 179
\end{tabular}

$\begin{array}{llllllllllllllllll}182 & 183 & 185 & 185 & 184 & 184 & 184 & 180 & 178 & 177 & 178 & 177 & 178 & 177 & 180 & 180 & 179 & 181\end{array}$ $182 \quad 108$ $\begin{array}{llllll}182 & 182 & 180 & 183 & 183\end{array}$ $189 \quad 189 \quad 189 \quad 188 \quad 188 \quad 188$

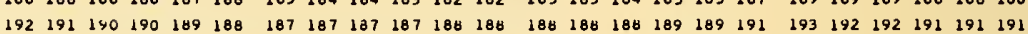

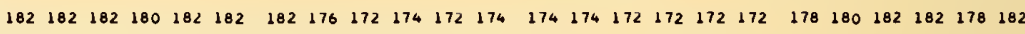

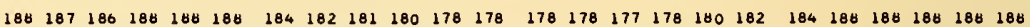

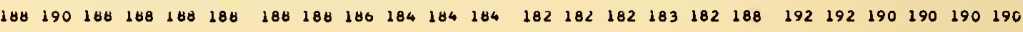

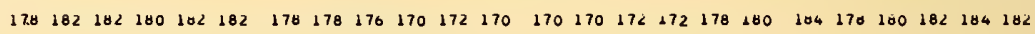

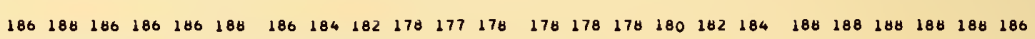

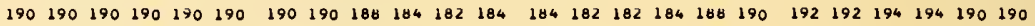
177

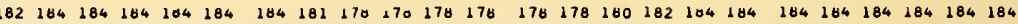
$\begin{array}{llllllllllllllllllllllll}186 & 186 & 186 & 186 & 186 & 188 & 186 & 186 & 184 & 182 & 182 & 178 & 180 & 182 & 182 & 188 & 186 & 188 & 188 & 190 & 190 & 190 & 186 & 186\end{array}$ $178 \quad 172$ 172

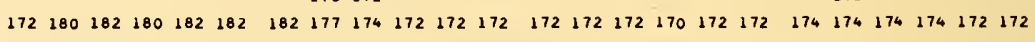

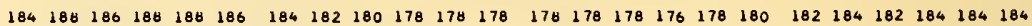
$\begin{array}{lllllllllllllllllllllllll}188 & 188 & 180 & 190 & 100 & 188 & 188 & 180 & 164 & 184 & 182 & 182 & 182 & 182 & 18< & 182 & 184 & 180 & 190 & 190 & 190 & 190 & 190 & 188\end{array}$

NOTE: THESE TABLES GIVE THE VALUE OF HOURLY MEDIAN SYSTEM LOSS EXCEEDED DURING THE

PERCENTAGE OF TIME SHOWN IN THE COLUMN HEADED TYPE. WHEN THE PERCENTAGE IS FOLLOWED BY

"E: THE TABULAR VALUE INCLUDES THE EFFECT OF SIGNALS PROPAGATED BY THE SPORADIC-E LAYER. WHEN THE CORRECTION IS ADDED TO THE HOUR SHOWN IN THE COLUMN HEADING THE RESULT IS PATH MIDPOINT TIME. 
TABLE II

(DATA FOR FIGURES 6 AND 7)

\section{SYSTEM LOSS - SPRING-FALL MONTHS}

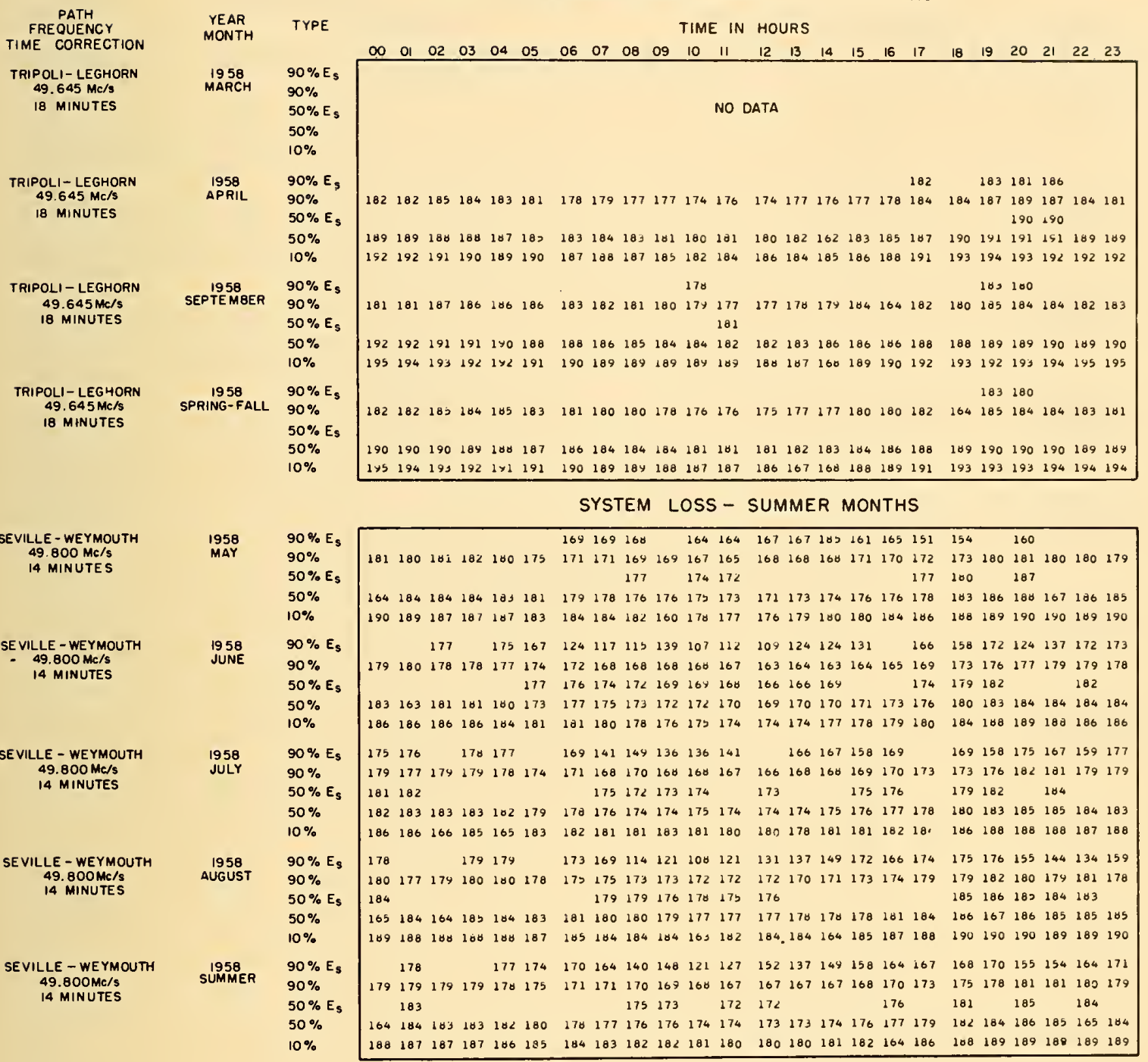


TABLE II

(OATA FOR FIGURE 7)

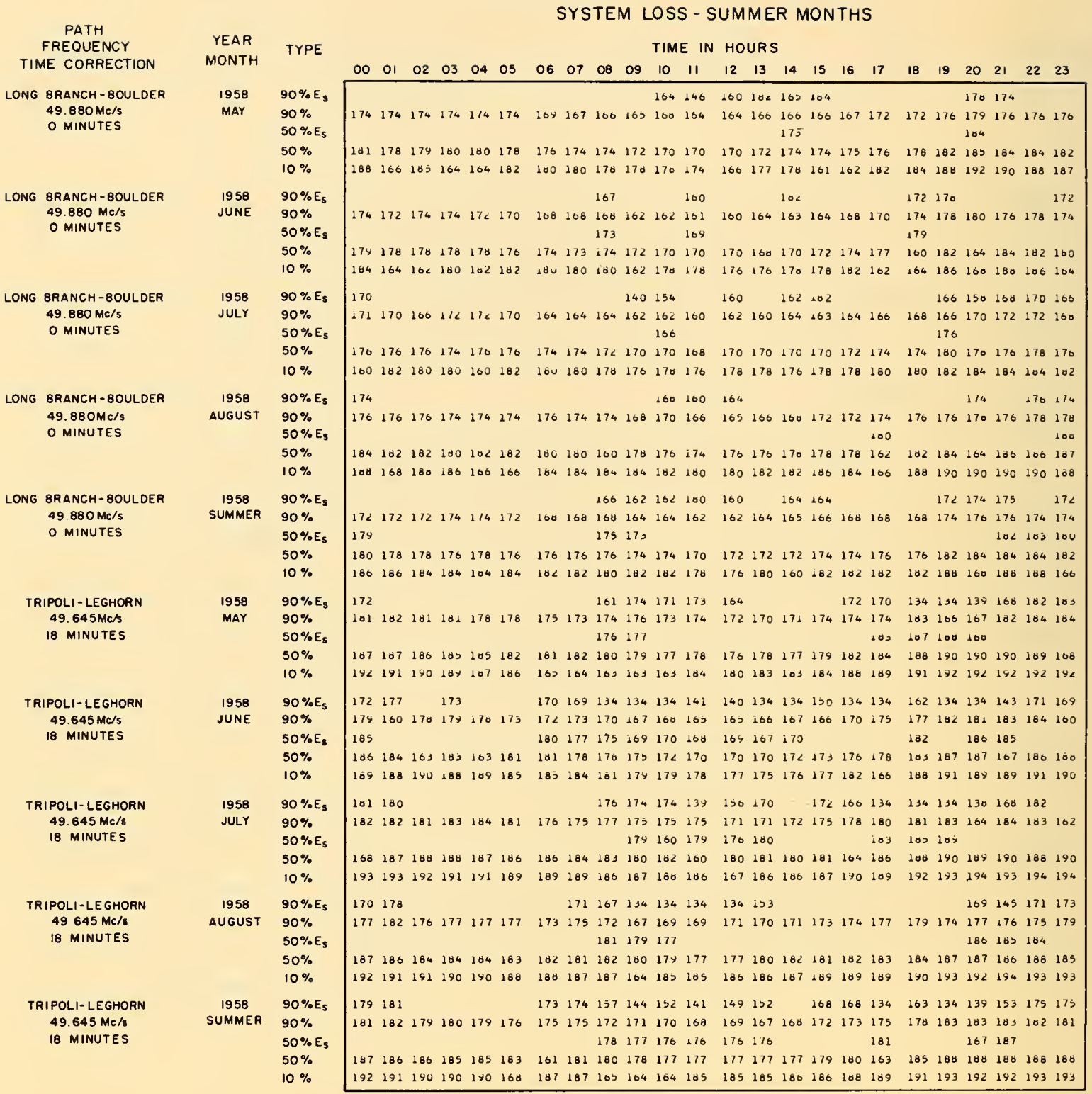


TABLE 五

(DATA FOR FIGURES 8 AND 9)

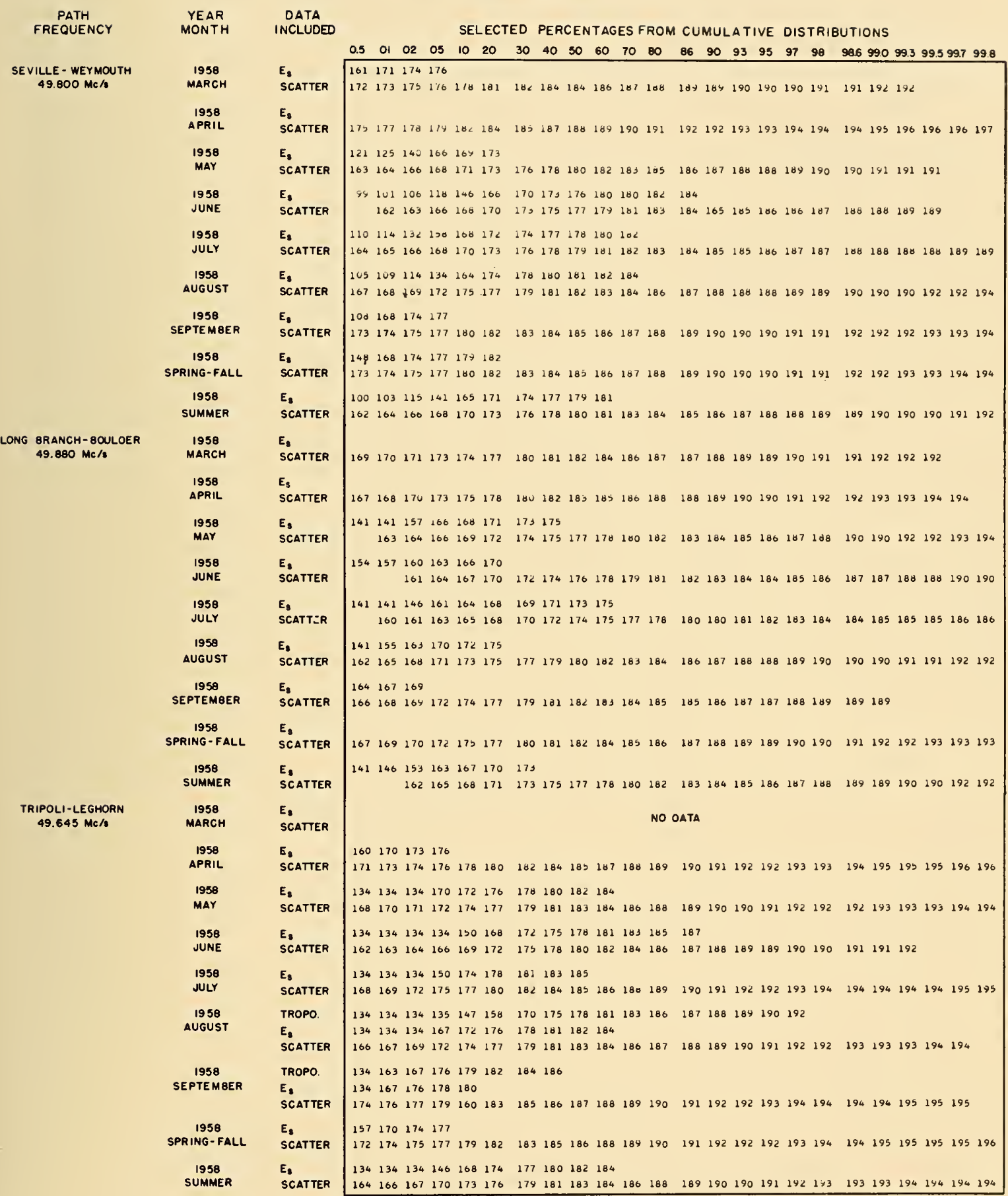




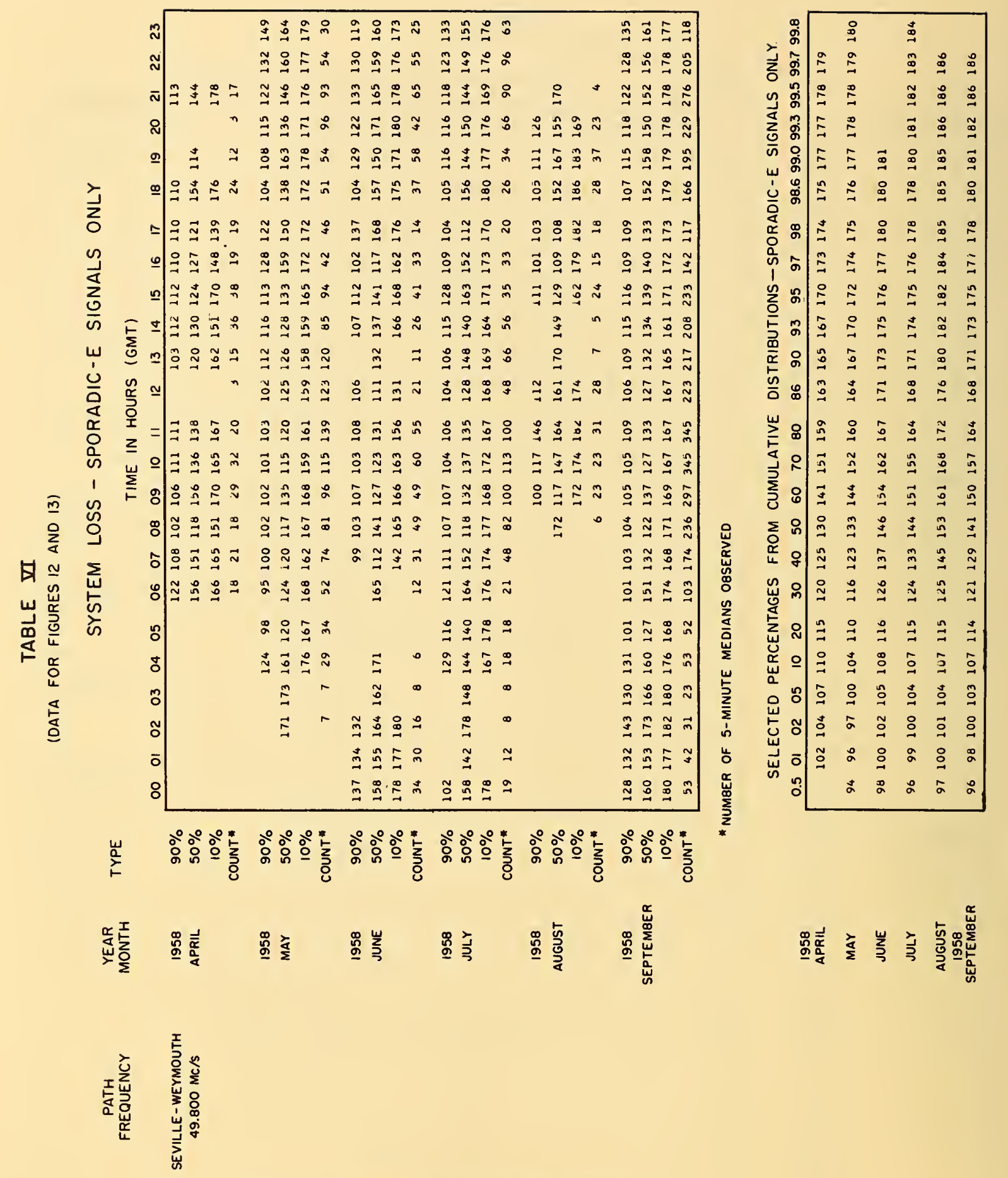

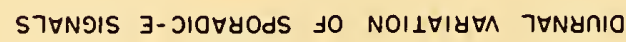




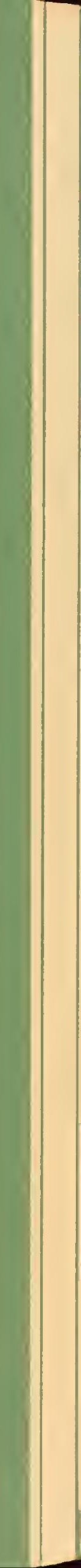




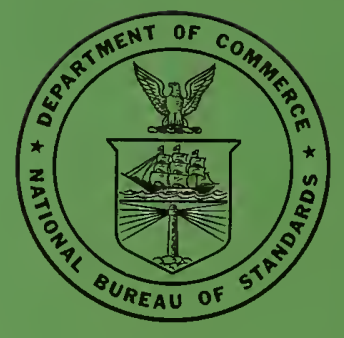

